\title{
Review \\ Zinc-Based Metal-Organic Frameworks in Drug Delivery, Cell Imaging, and Sensing
}

\author{
Rashda Safdar Ali, Hongmin Meng and Zhaohui Li * \\ Key Laboratory of Functional Nanomaterial and Medical Theranostics, Henan Joint International \\ Research Laboratory of Green Construction of Functional Molecules and Their Bioanalytical Applications, \\ College of Chemistry, Institute of Analytical Chemistry for Life Science, Zhengzhou University, \\ Zhengzhou 450001, China; Rashda-safdar@hotmail.com (R.S.A.); hmmeng2017@zzu.edu.cn (H.M.) \\ * Correspondence: zhaohui.li@zzu.edu.cn
}

check for

updates

Citation: Safdar Ali, R.; Meng, H.; Li, Z. Zinc-Based Metal-Organic Frameworks in Drug Delivery, Cell Imaging, and Sensing. Molecules 2022, 27, 100. https://doi.org/10.3390/ molecules 27010100

Academic Editors: Yuanfu Chen, Afang Zhang, Yiming Wang, Guankui Long, Qian Chen, Filipe Alexandre Almeida Paz and Stéphane Bellemin-Laponnaz

Received: 1 November 2021 Accepted: 22 December 2021 Published: 24 December 2021

Publisher's Note: MDPI stays neutral with regard to jurisdictional claims in published maps and institutional affiliations.

Copyright: (C) 2021 by the authors. Licensee MDPI, Basel, Switzerland. This article is an open access article distributed under the terms and conditions of the Creative Commons Attribution (CC BY) license (https:// creativecommons.org/licenses/by/ $4.0 /)$.

\begin{abstract}
The design and structural frameworks for targeted drug delivery of medicinal compounds and improved cell imaging have been developed with several advantages. However, metal-organic frameworks (MOFs) are supplemented tremendously for medical uses with efficient efficacy. These MOFs are considered as an absolutely new class of porous materials, extensively used in drug delivery systems, cell imaging, and detecting the analytes, especially for cancer biomarkers, due to their excellent biocompatibility, easy functionalization, high storage capacity, and excellent biodegradability. While $\mathrm{Zn}$-metal centers in MOFs have been found by enhanced efficient detection and improved drug delivery, these $\mathrm{Zn}$-based MOFs have appeared to be safe as elucidated by different cytotoxicity assays for targeted drug delivery. On the other hand, the MOF-based heterogeneous catalyst is durable and can regenerate multiple times without losing activity. Therefore, as functional carriers for drug delivery, cell imaging, and chemosensory, MOFs' chemical composition and flexible porous structure allowed engineering to improve their medical formulation and functionality. This review summarizes the methodology for fabricating ultrasensitive and selective Zn-MOF-based sensors, as well as their application in early cancer diagnosis and therapy. This review also offers a systematic approach to understanding the development of MOFs as efficient drug carriers and provides new insights on their applications and limitations in utility with possible solutions.
\end{abstract}

Keywords: Zn-MOFs; drug delivery; cell imaging; sensors

\section{Introduction}

Metal-organic frameworks (MOFs) are fascinating hybrid porous materials formed by a combination of metal and organic compounds [1,2]. The coordinated organic ligand serves as linkers between varied metal interiors [3]. Kinoshita and colleagues published the first report on metal-organic frameworks in 1959. Later, in the 1990s, Hoskin and Robson raised interest in this class of materials by adopting further logical methods to its "reticular" layout and synthesis [4]. These hybrid MOFs are found in one-dimensional, two-dimensional, or three-dimensional structures [5]. The primary objective for the development of MOFs was to achieve the desired characteristics by tuning their composition via changing either the metal or the organic component compared to their individual components [6]. MOF cavities permit the encapsulation of different guest molecules to allow drug release and optimal imaging $[7,8]$. If the volume of MOFs particles has been reduced to the nanoscale, nano-MOFs (NMOFs) could function as effective nano carriers to supply agents for imaging, chemotherapy, photo thermal therapy, photodynamic treatment, and rehabilitation [9].

There are certain properties associated with MOFs, such as their versatile architecture, increased internal surface area, and ease of tuning their configuration by altering any of their components, i.e., either metal or organic ligand, that make them ideal candidates for applications in drug delivery systems, imaging, and sensors [10]. Therefore, the selection of components in MOFs should be such that it is environmentally and biologically compatible [11]. 
It is imperative to ensure the non-toxicity of MOFs for their successful application in biological domains such as intracellular imaging and drug carriers [12-14]. In such instances, an important factor in designing MOFs is the likelihood to create mixtures of bioactive cations $\left(\mathrm{Ca}^{2+}, \mathrm{Zn}^{2+}, \mathrm{Ag}^{+}\right.$, and $\left.\mathrm{Fe}^{2+} /{ }^{3+}\right)$ with bioactive molecules as organic linkers that can medicinally transfer the component of interest through degradation of the framework [15]. MOFs appeared to possess various unique characteristics over conventional nanocarriers such that they can be easily undergo modification (in situ synthetic or postsynthetic modification) $[16,17]$, which have made them ideal compared to conventional nanocarriers [18].

In recent years, many review studies have been published on MOFs and its applications [19-21]. Modifications in design and type of organic ligand (such as phosphonates, imidazolates and carboxylates, etc.) and metal (i.e., $\mathrm{Ca}, \mathrm{Fe}, \mathrm{Ag}$, and $\mathrm{Zn}$, etc.) result in the fabrication of such MOFs that have utmost tunable porosities, rendering them perfect choices for holding, storage, and formation of effective drug delivery structures; and encapsulation of drugs, active gases, cosmetics, imaging, and effective theranostics [22-27]. However, to our knowledge, no review has been published, especially on the developments of Zn-MOFs nano carriers for drug delivery, cell imaging, and sensing applications, as summarized in Figure 1. Zinc, as an endogenous low-toxic transition metal cation, has become an ideal candidate in the preparation of zinc-based MOFs for applications in the biological system particularly as drug carriers [28]. In addition, zinc has been extensively used in dermatology a skin moisturizing with astringent, antibacterial, and anti-inflammatory properties $[29,30]$.

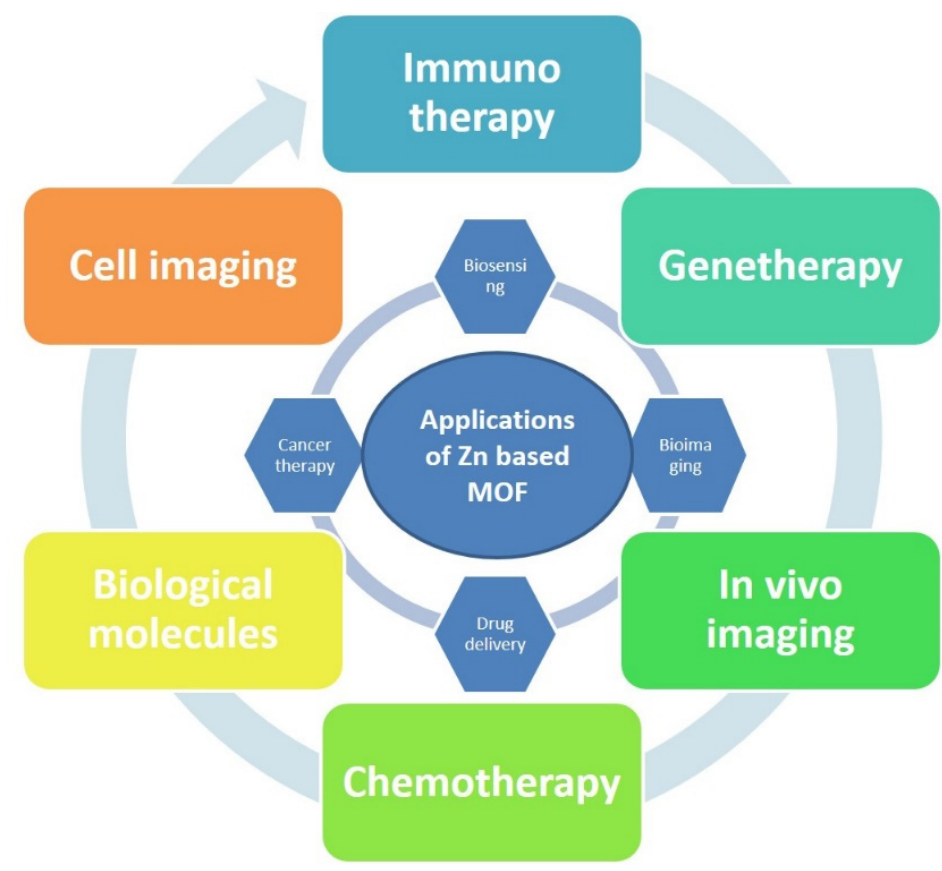

Figure 1. Summary of Zn-based MOFs applications.

The broad inner surface area and the flexible architecture of MOFs make them successful competitors for the production of developed drug delivery systems, sensing, and imaging [31,32]. Hydrophilic/hydrophobic interactions may be demonstrated by MOFs, and even a versatile arrangement that allows their porosity to be modified relative to physical and chemical properties for various drugs or gas can be obtained [33,34]. In most biographies, for example, biological processes, such as systems of drug delivery or nontoxic MOFs, were certainly preferred rather than toxic ones in intracellular imaging. The chemical stability of zinc ions as the desired component is recognized in bioapplication domains for implementing Zn-based MOFs, particularly as carriers of drugs [35-38]. Therefore, MOFs 
must be recognized for various applications, structured from naturally and chemically mediated essential elements that are competitive with the environment. However, in most research, non-toxic MOFs were preferred in intracellular imaging than toxic ones [39,40].

\section{Synthesis of Zn-Based MOFs}

Mechano-chemical, hydrothermal, microwave-assisted, and ultrasound procedures have been adopted to develop MOFs with practical attributes and desired texture [41-43]. The prime benefit of creating MOFs is the possibility of tuning their structure and functionality during their fabrication, where guest compounds bind and react with open sites. The selection of suitable building blocks during reticular synthesis ensures the creation of predefined shapes cavities. Using these approaches to make MOFs allows you to tune their structure and operation throughout the fabrication process, where visitor compounds can connect to vacant spaces and react with them $[44,45]$. Various iso-reticular MOFs formulations have been prepared with zinc-based octahedral clusters $\left(\mathrm{Zn}_{4} \mathrm{O}(\mathrm{CO})_{2}\right)$ serving the metallic centers surrounded by varied organic dicarboxylate nexus, thus constituting contrary 3D cubic structures [46,47]. The free and fixed pores diameters range at 3.8-19.1 $\AA$ and 12.8-28.8 $\AA$ in isoreticular MOF-1 (IRMOF-1) and isoreticular MOF-6 (IRMOF-16), respectively $[48,49]$. However, altering the organic linkers in MOFs variates the pore dimensions of the resulting framework and creates those with variable affinities for guest compounds [50]. For example, as the organic linkers are altered in IRMOFs, selective hydrogen adsorption and diffusion in the porous structure are varied [51].

\subsection{Hydro or Solvo/Thermal Technique}

Previously, the hydrothermal technique was used for producing coordinated metalorganic composites [52,53]. The problem encountered during the formation of these composites was the exclusion of remaining solvent from the matrix of MOFs caused by external heating. On the other hand, high temperatures could risk the composition of developed MOFs, which can be cut down by low-temperature solvent removal [54,55]. However, Zn-based MOFs that have been synthesized with stable thermal and chemical properties were reported [56]. In particular, hydrothermal, microwave-hydrothermal, and microwavesolvothermal methods are very low-temperature methods for processing nanophase materials of various sizes and shapes. These procedures conserve energy and are environmentally sustainable since the reactions take place in discrete, closed system environments. Using the above methods, the nanophase materials can be produced in either a batch or continuous process. This takes a long time (typically half to several days) and requires high energy (over a thousand watts) relative to the traditional hydro/solvothermal heating system [57]. One set of MOFs was released in 2013. 1-dinebsional chains of tetrahedral $\mathrm{ZnO}_{2}(\mathrm{OH})_{2}$ and octahedral $\mathrm{ZnO}_{2}(\mathrm{OH})_{2}$ combine together by a 3-hydroxy bridging agent and produces $\mathrm{Zn}_{2}(\mathrm{BTC})(\mathrm{OH})\left(\mathrm{H}_{2} \mathrm{O}\right) 1.67 \mathrm{H}_{2} \mathrm{O}$. The carboxylate groups of BTC moieties also connect octahedral and tetrahedral entities. The $\left[\mathrm{Zn}_{2} \mathrm{O}_{6}(\mathrm{OH})\left(\mathrm{H}_{2} \mathrm{O}\right)\right] n$ chains are linked in this manner to form an expanded three-dimensional structure [58].

\subsection{Electrochemical Method}

For the first time, the mixed-ligand MOF [Zn(1,3-bdc)0.5(bzim)] was effectively synthesized electrochemically in this study. It discovered that the amount of current and reaction time were the important elements influencing quality and yield. The authors were able to synthesize pure desirable MOF (crystallite size of $32.3 \mathrm{~nm}$ ) with a substantially greater products $(87 \%)$ compared to previously reported methods such as hydrothermal, solvothermal or slow diffusion techniques. Furthermore, reaction time was reduced from at least 8 days (solvothermal approach) to only $2 \mathrm{~h}$. According to early UV-Vis measurements, the material absorbed a large quantity of Ibuprofen $(163.9 \mathrm{mg} / \mathrm{g})$, which was comparable with the result found by ${ }^{13} \mathrm{C}-\mathrm{NMR}$ spectroscopy $(160.7 \mathrm{mg} / \mathrm{g})$ [59]. 


\subsection{Ultrasound Methods}

Environmentally friendly and budget friendly nanoscale MOFs have been synthesized by developed ultrasound methods [60]. The ultrasonic technique is more effective in fabricating Zn-based MOFs with fluorescent characteristics, mainly for the accurate sensing of ethylene amine. Similarly, as demonstrated in Figure 2, varying the sonication time can result in the different morphologies of $\mathrm{Zn}$-based MOFs, i.e., nano sheets, nano belts, and microcrystals [61]. An example is [ $\left.\left[\mathrm{Co}_{2}(\mathrm{TATAB})(\mathrm{OH})\left(\mathrm{H}_{2} \mathrm{O}\right) 2\right] \cdot \mathrm{H}_{2} \mathrm{O} \cdot 0.6 \mathrm{O}\right]$. In order to create nanostructures, the experiment was first constructed in an autoclave for $72 \mathrm{~h}$ at $180^{\circ} \mathrm{C}$ and then irradiated for $15 \mathrm{~min}$ with ultrasound $(80 \mathrm{~W})$. Ultrasounds, on the other hand, have reduced the response time to $2 \mathrm{~h}$ [62]. In comparison to previous approaches, ultrasonic irradiation reduces response time while simultaneously improving particle size and shape. [ $\left.\mathrm{Zn}_{2}\left(\mathrm{NH}_{2}-\mathrm{BDC}\right) 2(4-\mathrm{bpdh})\right]$ is a $\mathrm{Zn}(\mathrm{II})$-based MOF. 3,4-bis(4-pyridyl)-3,4-diaza-2,4-hexadiene, $\mathrm{DMF}=\mathrm{N}, \mathrm{N}$ dimethylformamide) is made $\left(\mathrm{NH}_{2}\right.$ $\mathrm{BDC}=$ amino-1,4benzenedicarboxylate,4-bpdh=2,5-bis(4-pyridyl)-3,4-diaza-2,4-hexadiene, $\mathrm{DMF}=\mathrm{N}, \mathrm{N}$ dimethylformamide). The direct pyrolysis of S-TMU- $16 \mathrm{NH}_{2} \mathrm{MOF}$ was used to produce $\mathrm{ZnO}$ octahedral nanostructures in a simple and easy manner [63]. Two 3D porous Zn-based MOF prepared by the sonochemical process is [ $\mathrm{Zn}(\mathrm{oba})(4-\mathrm{bpdh}) 0.5] \mathrm{n} \cdot(\mathrm{DMF}) 1.5$ (TMU-5) and the other one is [Zn(oba)(4-bpmb)0.5]n (DMF)1.5 (TMU-6). Further calcination of these MOFs at $550{ }^{\circ} \mathrm{C}$ enhances RhB adsorption. The conclusion is that by changing the sonication time, we can achieve MOFs with different morphologies, sizes, and shapes via ultrasound-assisted irradiation methods [64,65]. [ $\mathrm{Zn}\left(\mathrm{NH}_{2}-\mathrm{BDC}\right)\left(4,4^{\prime}\right.$-bpy) is a 1.7-micrometer-sized $\mathrm{Zn}$-based MOF synthesized in $60 \mathrm{~min}$ by ultrasound method. Moreover, this combination of $\mathrm{Al}^{3+}$ and $\mathrm{NH}_{2} \mathrm{BDC}$ ligand induces an excellent potential as the fluorescent sensor for low limit detection of toxic $\mathrm{Al}^{3+}$ and methanol in MOFs [66].
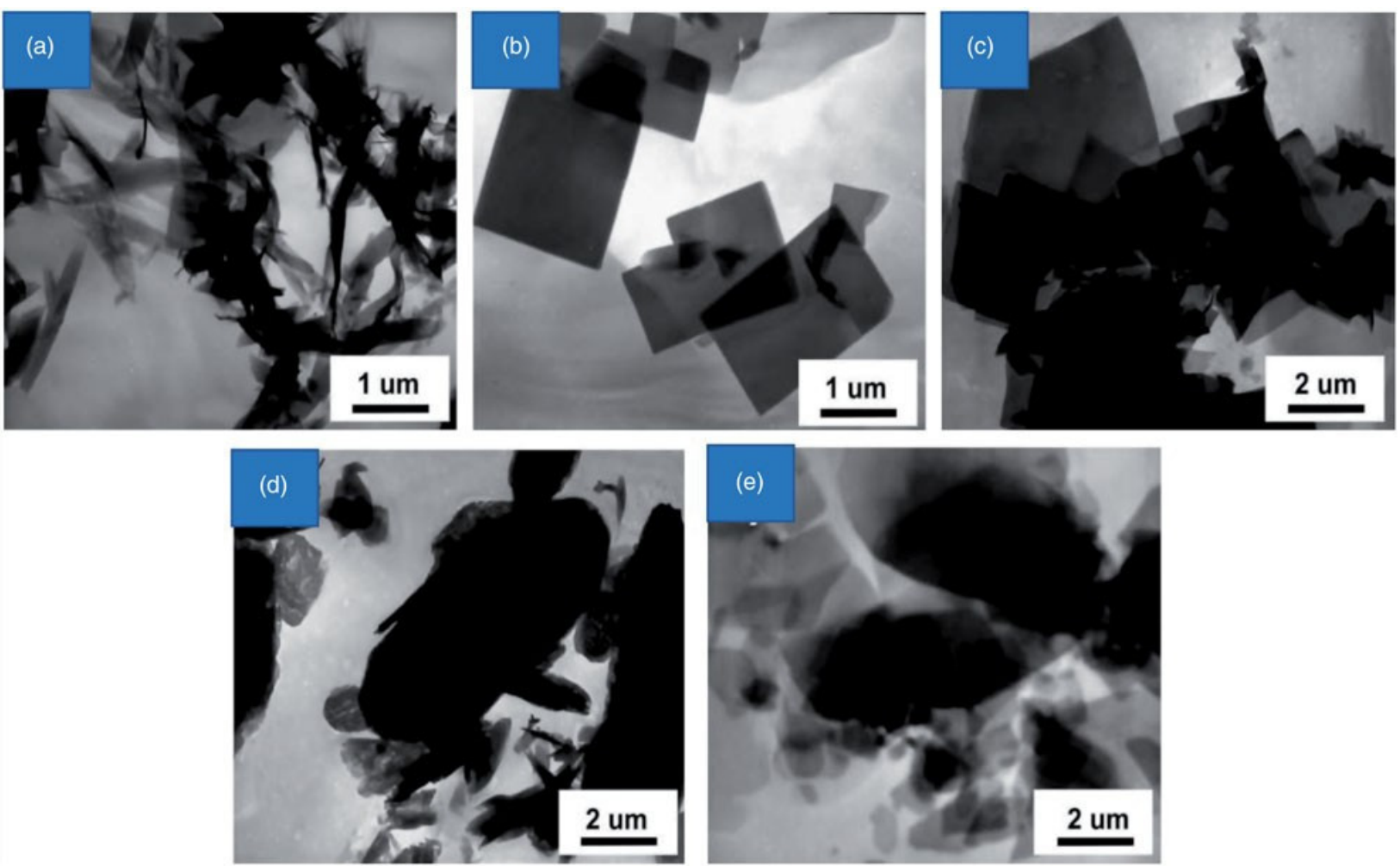

Figure 2. The transmission electron microscopic (TEM) result of $\left[\mathrm{Zn}(\mathrm{BDC})\left(\mathrm{H}_{2} \mathrm{O}\right)\right] \mathrm{n}$ following (a) 10 , (b) 20, (c) 30, (d) 60, and (e) 90 min sonication [61]. Reprinted with permission from Ref. [61]. Copyright 2008 Elsevier. 
Under ultrasonic irradiation, several chemical processes have been performed in high yield with reduced reaction durations [67]. The interaction of $\mathrm{Zn}(\mathrm{OAc})_{2}$ and $\mathrm{H}_{2} \mathrm{BDC}$ in DMF during ultrasonic irradiation for 10 min yielded nanostructures with a breadth of 150-300 $\mathrm{nm}$ and a height of 2-5 $\mu \mathrm{m}$. Whenever the response time was too long at $20 \mathrm{~min}$, nanoparticles became larger in size. Having diameters ranging from $300 \mathrm{~nm}$ and length ranges $2 \mu \mathrm{m}$, such nanomaterials have regular quadrate morphologies. Improvements in reaction time were reflected in a $1.5 \%$ boost in nanostructures dimensions. However, when the reaction time was prolonged beyond $60 \mathrm{~min}$, numerous microcrystals with size varying from hundred nanometers to tens of nanometers were obtained. Once reaction length increased to $90 \mathrm{~min}$, massive microcrystals could not be identified, although nanoparticles of various shapes and sizes and those that were irregularly shaped were observed. This result indicated that throughout long-term ultrasonic irradiation, $\mathrm{Zn}(\mathrm{BDC})\left(\mathrm{H}_{2} \mathrm{O}\right) \mathrm{n}$ microcrystals were degraded, and all these microcrystals were transformed into nanoparticles caused by weak covalent bonding among 2D conjugated polymers.

\subsection{Microwave}

The microwave-assisted method is another budget-friendly technique for developing zinc-based MOFs that supplements benefits including improved reaction rate, practical assessment of process parameters, and control over facile morphology [68]. Meanwhile, this method is considered more suitable due to the synthesis of MOFs from novel material and narrow particle size distribution [69]. Microwave-assisted chemical precipitation is an excellent approach for incorporating b-estradiol. Moreover, the nano-sized crystals of Cr-MIL-101 were obtained by microwave heating at $210{ }^{\circ} \mathrm{C}$ in 2011 [70].

However, Sabouni with his team first recorded microwave-assisted production of CPM-5 in 2012 [71]. Microwave-assisted heating is a greener technology for synthesizing materials in a quicker timescale (a few minutes to hours) and with lower power consumption due to direct and uniform heating (hundreds of watts). Figure 3 illustrates how well the crystal shape of MMOF-5 changes as illumination duration advances. MMOF-5 crystal faces showed smooth and shiny during 15 to $30 \mathrm{~min}$; however, as illumination frequency increased, interface imperfections developed. The polymeric binder inside the precipitated MMOF-5 appears to dissolve between 45 and $60 \mathrm{~min}$, producing instability [72].

\subsection{Templated Synthesis}

Because of their capacity to regulate crystal growth, form, and secondary porosity, template-directed approaches for the synthesis of MOFs have opened up new areas in materials research. The template was utilized to direct the evolution of MOFs toward better nano-architectures with enhanced functions. In general, hard templates for creating the nanoscale MOFs, including semi-sacrificial, sacrificial, and non-sacrificial hard templates, have been provided in the literature. Due to the fact that considerable template-based synthesis research has been published in a number of recent publications, we will discuss a few instances of template-based synthesis below. 


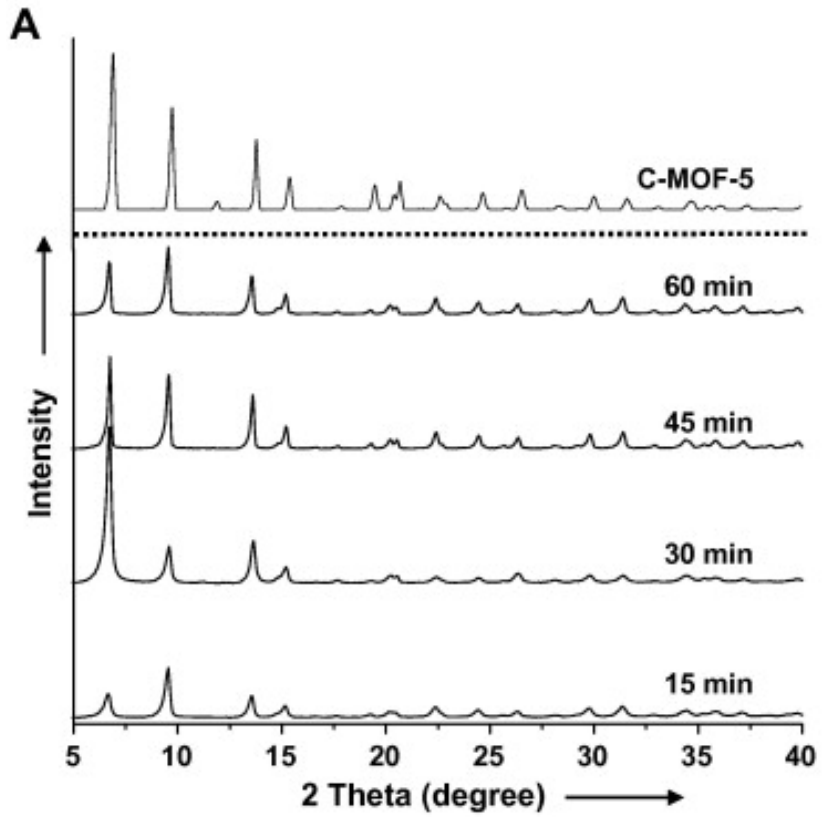

B
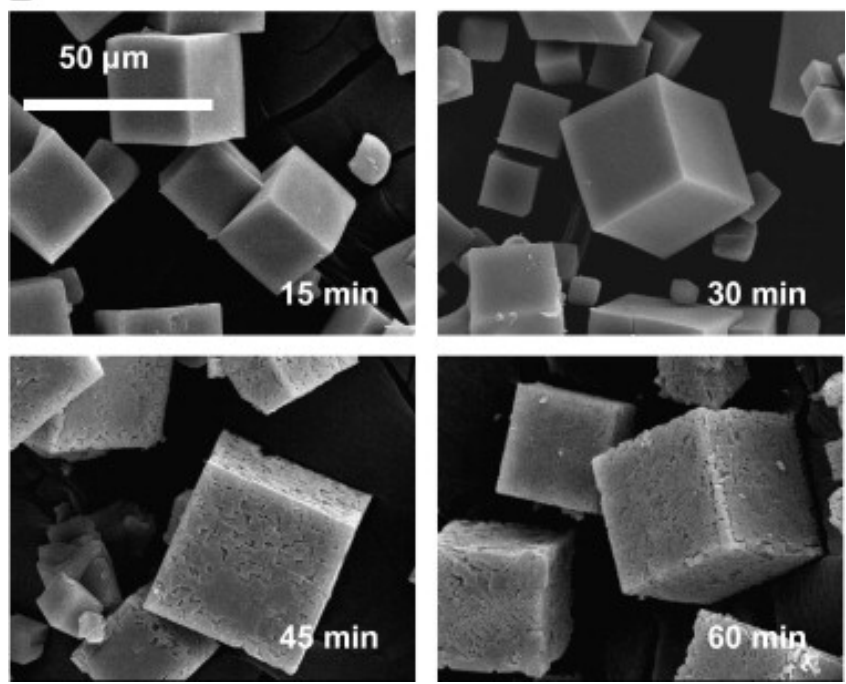

Figure 3. (A) XRD and (B) SEM images of MMOF-5 samples: microwave power was supplied at 600 W [72]. Reprinted with permission from Ref. [72]. Copyright 2008 Elsevier.

Hwang and colleagues presented a simple but productive synthesis process for MOFs in regulated polymorphism, crystalline shape, and size that could be carried out under ambient air conditions. The influence of solvents on ZBD synthesis was explored firstly in a meaningful manner in this study by varying the kind and concentration of the solvents. The solvent template effect allows for the synthesis of one-dimensional rod-like ZBDh in DMF and two-dimensional plate-like ZBDt in MeOH. The control of crystallite size and aspect ratios was performed by combining $\mathrm{DMF} / \mathrm{MeOH}$ in different ratios such as a co-solvent. Each solvent acts as a crystal modulator, slowing nucleation and increasing crystal size; for example, increasing the concentration of $\mathrm{MeOH}$ increases the crystal size of ZBDh. The architecture shifts from 1-dimensional rods to 2-dimensional plates when $\mathrm{MeOH}$ is added. As a proof of concept, the resulting ZBDs were dynamically transformed into hexagonal rod-nanoporous and tetragonal plate-nanoporous carbons for usage in EDLCs. The produced ZBDs were cylindrically polymerized to hexagon shaped rod and tetragonal plate nanoporous carbons and used as energy storage devices to help in finding basic morphology-volumetric capacitance correlations in supercapacitors [73]. 
Hou's group reported a self-templated technique for constructing a hydrangea-like framework of open carbon cages using morphology-controlled thermal alteration of core@shell MOFs. Direct polymerization of core@shell zinc (Zn)@cobalt (Co)-MOFs yields open wall nitrogen-doped carbon cages with well-defined walls. Upon the introduction of guest iron (Fe) ions into the core@shell MOF precursor, the open carbon cages self-assemble to construct a hydrangea-like 3D structural frame. This system is interconnected by carbon nanotubes, which are expanded in situ on Fe-Co alloy nanoparticles constructed during the pyrolysis of Fe-introduced Zn@Co-MOFs. This structural frame of open carbon cages displays effective bifunctional catalysis for both OER reactions, achieving great performance in $\mathrm{Zn}$-air batteries [74]. Li and colleagues utilized PS nanospheres with a diameter of $400 \mathrm{~nm}$ as a hard template to create hollow spherical ZIF-8 by spreading the ZIF-8 precursors $\left(\mathrm{Zn}^{2+}\right.$ and 2-methylimidazole (2-MeIm) and constructing a ZIF-8 shell on the surface of the PS nanospheres. The removal of PS from the framework by toluene treatment resulted in the creation of a hollow spherical ZIF-8. When ZIF-8 is manufactured without a template, the protein takes on a micron-sized dodecahedral structure with a non-hollow architecture. In the cycloaddition process of 1,3-cyclohexanedione, hollow spherical ZIF-8 materials and unsaturated aldehydes displayed a better conversion rate of 89 percent over extensively biosynthesized ZIF-8 material (73 percent). This improvement is feasible due to an increase in accessible surface area and, as a consequence, an improved active catalytic site for the cycloaddition process $[75,76]$.

Wang and colleagues devised a unique method for developing bimetallic $\mathrm{Zn}-\mathrm{Co}$ ZIFs by employing ZnCo-LDH as a sacrificial template (merged ZIF-8 and ZIF-67). In their approach, $\mathrm{ZnCo}-\mathrm{LDH}$ was first dispersed in a mixed solution of DMF and water (DMF:water = 10:1), followed by the addition of a preset quantity of 2-MeIm. This technique led the $\mathrm{Zn}-\mathrm{Co} \mathrm{LDH}$ to lose its identity and it transformed into a two-dimensional MOF structure. During the first four hours of the reaction period, ZnCo-ZIF nanostructures with a diameter of $100 \mathrm{~nm}$ started nucleating on the ZnCo-LDH's interlayer surface. Nonetheless, during the following $4 \mathrm{~h}$, packed ZnCo-ZIF polyhedra with compact flakelike shape formed, and 2-MeIm completely sacrificed LDH and reassembled into $\mathrm{Zn}-\mathrm{Co}$ ZIF. Following pyrolysis, this extensively intercalated ZnCo-ZIF formed a remarkable honeycomb-like macroporous structure with adjustable electrochemical and supercapacitance capabilities [77].

In a groundbreaking study, El-Hankari and colleagues used three distinct nanoshapes of $\mathrm{ZnO}$ (e.g., nanosphere, nanorod, and nanostar) coated with dodecyl guanidinium hydrochloride (C12Gua) as an etchable and sacrificial hard template for the growth of morphologically tunable ZIF-8 via a simple surface-passivation method. The reaction conditions carefully controlled the formation and development of ZIF-8 nanostructures (e.g., emulsifier type and amount, temperature, solvent, and time). It was also crucial to employ a suitable amount of C12Gua surfactant while controlling ZIF-8 development on $\mathrm{ZnO}$ nanostructure. One benefit of this method is the use of aqueous systems rather than volatile chemicals (such as $\mathrm{MeOH}$ and DMF) for etching the $\mathrm{ZnO}$ template. El-Hankari and colleagues used a PVP-assisted base etching approach to selectively remove the amphoteric $\mathrm{ZnO}$ core while preserving the ZIF-8 shell. Furthermore, since ZIF-8 was retained after etching, adding $\mathrm{Au}$ NPs to the $\mathrm{C} 12 \mathrm{Gua}$-coated $\mathrm{ZnO}$ core had no influence on the etching process. As a consequence, the Au NPs inside the ZIF-8 shell formed a hollow Au-ZIF-8 yolk-shell architecture. The authors also discovered that $\mathrm{ZnO}-\mathrm{ZIF}-8$ is a rhodamine $\mathrm{B}$ adsorbent. As a result, ZnO-ZIF-8 outperformed $\mathrm{ZnO}$ (5.8 percent) and ZIF-8 (38 percent) in terms of adsorption efficiency [78].

Won-Tae Koo and colleagues created nanosized Hollow Spheres of Catalyst-Loaded $\mathrm{ZnO} / \mathrm{ZnCo}_{2} \mathrm{O}_{4}$. In this study, the templating procedure using PS sphere and BM-MOF was employed to effectively functionalize ultrasmall Pd NPs on TMO HSs. The theorized $\mathrm{Pd}-\mathrm{ZnO} / \mathrm{ZnCo}_{2} \mathrm{O}_{4} \mathrm{HSs}$ have a high surface area and gas permeability due to their hollow design. By purposely breaking the $\mathrm{ZnO}$ phase, heterojunctions are also generated in the $\mathrm{Pd}-\mathrm{ZnO} / \mathrm{ZnCo}_{2} \mathrm{O}_{4}$ HSs. Furthermore, because of their small size and homogenous 
distribution, the NPs are an excellent catalyst for the complex production of $\mathrm{ZnO} / \mathrm{ZnCo}_{2} \mathrm{O}_{4}$ HSs. Pd- $\mathrm{ZnO} / \mathrm{ZnCo}_{2} \mathrm{O}_{4} \mathrm{HS}$ produced demonstrated extraordinarily strong selectivity toward acetone gas with remarkable sensitivity $\left(S=69\right.$ percent to $5 \mathrm{ppm}$ at $\left.250{ }^{\circ} \mathrm{C}\right)$ [79]. In addition, a list showing MOFs with their building blocks is shown in Table 1 [80-85].

Table 1. Details about recently developed Zn MOFs: their structure, drug loading and release rate.

\begin{tabular}{|c|c|c|c|c|c|c|c|}
\hline \multicolumn{2}{|c|}{ Zn-Based MOF } & bio-MOF-1 & IFMC-1 & Med-MOF-1 & $\begin{array}{c}{\left[\mathrm{Zn}_{2}(1,4-\right.} \\
\left.\text { bdc })_{2}(\text { dabco }) n\right]\end{array}$ & Zn-TBDA & MOF-74 \\
\hline \multicolumn{2}{|c|}{$\begin{array}{l}\text { Chemical/ } \\
\text { Empirical Formula }\end{array}$} & $\begin{array}{c}\mathrm{Zn}_{8}(\mathrm{Ad})_{4} \\
(\mathrm{BPDC})_{6} \mathrm{O}_{2} \\
\left(\mathrm{NH}_{2}\left(\mathrm{CH}_{3}\right)_{2}\right)+ \\
8 \mathrm{DMF}, 11 \mathrm{H}_{2} \mathrm{O}\end{array}$ & - & $\begin{array}{c}\mathrm{Zn}_{3} \\
\text { (curcumin })_{27} \\
(\mathrm{DMA})_{3} \\
\text { (ethanol) }\end{array}$ & $\begin{array}{l}{\left[\mathrm{Zn}_{2}(1,4-\mathrm{bdc})_{2}\right.} \\
\quad(\mathrm{dabco}) \mathrm{n}]\end{array}$ & {$[\mathrm{Zn}(\mathrm{tbda})]_{\mathrm{n}}$} & $\mathrm{Zn}_{2} \mathrm{DOT}$ \\
\hline \multicolumn{2}{|c|}{ Organic Linker } & Adenatite & Triazole & Curcumin & $\begin{array}{c}1,4- \\
\text { diazabicyclo } \\
{[2.2 .2] \text { octane }} \\
\text { (DBCO) }\end{array}$ & $\begin{array}{c}\text { 4'-(1H-tetrazol-5-yl)- } \\
{\left[1,1^{\prime} \text {-biphenyl]-3,5- }\right.} \\
\text { dicarboxylic } \\
\text { acid }\end{array}$ & $\begin{array}{l}\text { 2,5-di hydrox- } \\
\text { yterephthalic } \\
\text { acid }\end{array}$ \\
\hline & & Procainamide & 5-Fluorouracil & Ibuprofen & Ibuprofen & Methotrexate & Ibuprofen \\
\hline \multicolumn{2}{|c|}{ Loading Degree } & $0.22 \mathrm{~g} / \mathrm{g}$ & $30.48 w \mathrm{w} \%$ & $0.24 \mathrm{~g} / \mathrm{g}$ & $15 \mathrm{wt} \%$ & $12.59 \%$ & $313 \mathrm{k}$ \\
\hline \multirow{2}{*}{$\begin{array}{l}\text { Release } \\
\text { Rate }\end{array}$} & $\%$ & 20 & 89.8 & 97 & 80 & 61 & - \\
\hline & Time & $72 \mathrm{~h}$ & $120 \mathrm{~h}$ & $80 \mathrm{~h}$ & $288 \mathrm{~h}$ & $48 \mathrm{~h}$ & - \\
\hline \multicolumn{2}{|c|}{ Reference } & {$[80]$} & [81] & [82] & [83] & [84] & [85] \\
\hline
\end{tabular}

\section{Influence of Composition}

Biologically friendly composition of metal-organic frameworks has enabled their application in biomedical and environmental fields; however, different parameters, including their use, associated risks and benefits, distribution, degradation, accumulation in various organs and tissues, and excretion from the body, are set to decide one composite over the other [1,18]. Therefore, the selection of different metals and organic linkers at different rates depends on the aforementioned conditions [86]. On the other hand, the most suitable options for the inorganic part of composites include calcium, zinc, magnesium, iron, and zirconium, and the selection of specific metal relies on its lethal toxicity [87]. The other advantage of organic linkers is their functionalization, providing the option of creating a combination of different types of organic functionalities, thus altering the physical and chemical properties of the solid. An earlier study, for example, documented the synthesis of certain MOF composites in the presence of polyoxometalates, sulfonates, amines, phenolates, and imidazolates. Another benefit of organic linkers is their functionalization, which allows for the creation of either all-through or after-the-fact combinations of various kinds of organic functionalities (i.e., apolar and polar), hence modifying the physical and chemical properties of the solid. In the presence of POMs, Liu and colleagues synthesized some MOF composites (the production procedure was quite similar to the BAS technique), dubbed NENU-n, from in situ synthesis of MOFs (HKUST-1) [88]. Ishida et al. employed a solid grinding process to make Au-MOF composites by grinding Au particles with MIL53(Al), MOF-5, and HKUST-11 [89]. As a result, MOF composites, in which MOFs are combined with a variety of useful materials, have been created to compensate for the flaws of individual components. MOFs can be combined with zero-dimensional materials such as nanoparticles and quantum dots to create new materials, one-dimensional materials such as nanorods, nano tubes, and nanobelts, two-dimensional nanosheet materials, and three-dimensional MOF composites such core-shell and cubic composites. In this review, we address recent breakthroughs in MOF and their advanced synthetic methods as well as their various applications, especially related to drug delivery, cell imaging, chemo sensing, and also some electrochemical applications such as supercapacitors, sensors, catalysts, and also batteries, based on their measurements. With yields of up to 99 percent and a catalyst loading of 3 mol percent, the chemical displayed significant activity as a heterogeneous catalyst, notably with cyclic secondary amines and saturated aliphatic aldehydes 41 [90]. 
Exogenous linkers are either synthetic or ones orignating from natural origins that would not interfere in normal functions in body. Exogenous organic linkers used in MOFs are made from zinc named as zinc adeninate- $4,4^{\prime}$ biphenyl dicarboxylate BioMOF- 1 . Another option for selection of organic linkers is the one that are a constructive part of body composition. These linkers are ideal in term of their application in living cells, because of their least possible adverse effects when administered in the body. Several metal organic frameworks with such organic linkers have been developed so far. An example of MOF based on endogenous linker is a porous zinc amino acid metal organic framework that depicts a flexible framework having potential to accommodate carbon dioxide [91].

\section{1. $p H$-Responsive Zn-MOFs Nanocarrier}

Another achievement in the use of MOFs based on Zn metal for medical field uses is the design of pH-dependent medicinal carriers. Polyacrylic acid@zeolitic imidazolate framework-8 (commonly known as PAA@ZIF-8) possesses an improved doxorubicin (DOX) loading capacity of around $1.9 \mathrm{~g} / \mathrm{g}$, which is an anticancer drug. This is attributed to the electrostatic reactions between the positively and negatively charged DOX and PAA, respectively, and coordination interaction among $\mathrm{Zn}^{2+}$-doxorubicin. It has been found by using confocal laser scanning microscopy analysis that drug-loaded MOF releases quickly at a $\mathrm{pH}$ value of $5.5 \mathrm{in}$ a buffer solution rather than at a neutral $\mathrm{pH}$ of around 7.4 [92].

One of the medication mechanisms of distribution of 5-FU@ZIF-8 (5-FU = 5-fluorouracil) has been reported recently [93]. The medication delivery system does have a $66 \%$ therapeutic efficacy and $\mathrm{pH}$-responsive drug dissolution technology. Inside drug dissolution research, 5-FU had just been launched quickly at pH 5.0 as compared to those at acid levels 7.4, with rather upwards of $45 \%$ of both the drug expelled between one hour at acidic $\mathrm{pH}$, particularly in contrast with only $17 \%$ at $\mathrm{pH}$ 7.4. The research has always used $\mathrm{pH}$-responsive NMOFs in DDS for drug delivery applications, and it can also be used by researchers who want to learn more about $\mathrm{pH}$-responsive MOFs. ZIF-8's size and functionalization, on the other hand, should be evaluated from a biological point of view, as its morphologies influence cancer cell ingestion rates. However, the intricacy of the human body's environment restricts the capacity of single stimulus-responsive Zn-NMOF drug carriers to accurately distribute pharmaceuticals in the body [94]. In order to counter the aforementioned disadvantage, different $\mathrm{Zn}$-based carrier systems were adopted with various stimuli-responsive as a superior option to boost delivery capacities and chemotherapeutic efficiency. In this study, they concentrate on the subject of $\mathrm{pH}$-responsive agents based on $\mathrm{Zn}$-based MOFs that has emerged in the past 20 years. UCNPs@ZIF-8/FA had a 5-FU extraction efficiency of up to $71 \%$ to $82 \%$ at approximate $\mathrm{pH} 5.5$ after 12 and $24 \mathrm{~h}$ equally in an in vitro drug release experiment over $\mathrm{pH}$ 7.4; however, only 35\% was reported when ZIF-8 quickly dissolved in the acid medium [95].

\section{2. $p H$-and Temperature Responsive Zn-MOFs Nanocarrier}

Lin and his team developed a $\mathrm{pH}$ and temperature-dependent drug release framework with one-dimensional channels and from constituents such as zinc ions and bifunctional ligands. The developed framework, Zn-TBDA (TBDA $\frac{1}{4} 4^{\prime}$-(1H-tetrazol-5-yl)-[1,1'-biphenyl]3,5-dicarboxylic acid), showed insignificant cytotoxic activity and depicted an appropriate methotrexate holding potential and controlled release. The dual temperature and $\mathrm{pH}$ responsive release of encapsulated drug of this complex metal organic framework established its ability as an efficient drug/medicinal carrier [96]. Another zinc based MOF was prepared with tricarboxylic ligand for the storage and delivery of 5-fluorouracil and the resultant structure represented appropriate window size, better BET surface area, and improved density of open free $\mathrm{N}$ sites. The developed framework showed $\mathrm{pH}$ responsive behavior by releasing $68.6 \%$ of the stored 5 -fluorouracil at a $\mathrm{pH}$ of 6.5 that was increased to $86.5 \%$ at $\mathrm{pH}$ of 5.0 after $24 \mathrm{~h}$. Additionally, the toxicity of synthesized framework was also measured for HepG2 and HFL1 by performing MTT assay, and it showed satisfactory results [97]. 
Doxorubicin (DOX) has been extensively explored as a standard anticancer treatment $[98,99]$. There was a one-pot procedure that was used to make homogeneous nanoscale DOX@ZIF-8. DOX@ZIF-8 remained stable after 7 days at $60{ }^{\circ} \mathrm{C}$ and pH 7.4 diluted PBS solutions, while the ZIF-8 carrier discharged around 90\% of DOX at pH 5.5 because its framework became denatured in high pH solutions. DOX@ZIF-8 was more effective against human breast cancer cells versus free DOX in the MTT testing. In viable cells, the MTT test demonstrated no cytotoxicity, revealing that the NPs might be employed as biodegradable DDS in the next.

A one-pot encapsulation procedure was used to create the core-shell nanostructure utilizing BSA/ DOX and ZIF-8 [100]. The fundamental nanostructure protected the activity of BSA, which increased the efficacy of DOX and reduced adverse medication effects. The addition of positive charges to BAS/surfaces DOX's will also boost its cellular absorption. Similarly, drug release assays revealed that only $84 \%$ of the pharmaceuticals were expelled after 1 day at $\mathrm{pH} 7.4$; on the other hand, they discharged nearly all of the medicines at about the same period at $\mathrm{pH}$ 5.5. Finally, the $\mathrm{pH}$-responsive characteristic of the foundational ZIF8 substance permitted it to regulate the untimely emission of DOX in defined circumstances. BAS/DOX@ZIF-8 outperformed pure DOX, BAS/DOX, and ZIF-8 in regards to biomedical applications and lethality, which can be attributable to their complex formation. With $\mathrm{pH}$ responsive properties and antitumor medical therapies, the novel fundamental DDS will become an exciting technology. One method also has been used to create an ionic strength ZnO-DOX/ZIF-8 DDS to control early drug delivery and improve medicine therapeutic effictivness in tumor tissue.

At $\mathrm{pH} 7.4$, about $20 \%$ of DOX was liberated through DDS, although in the $\mathrm{pH} 5.5$ buffer, it was predicted to be around $84 \%$. Due to the fact that the DOX with radical oxidation products generated synergic activity, ZnO-DOX/ZIF-8 exhibited higher cellular uptake and lethality over DOX as well as ZnO@ZIF-8. These results pointed to the $\mathrm{ZnO}$ DOX@ZIF-8 transporter as an effective $\mathrm{pH}$-responsive drug carrier strategy for treatment for cancer. New functionalized DOX@ZIF-8 NPs enabling endo/lysosomal egress with pH-responsive liberation in the cellular environment were discovered [101].

The aptamer (AS1411) transplanted on the ZIF-8 may boosts malignant cells absorption while minimizing DOX negative consequences. The customized aptamer also exhibited great $\mathrm{pH}$-responsive drug dissolution capabilities, with only $5 \%$ of DOX discharged from NPs within $24 \mathrm{~h}$ under PBS (pH 7.4) and 50\% pharmaceutical unloaded in highly acidic (pH 5.0). Pursuant to in vitro drug experiments, NPs liberated $22.5 \%$ and $26.72 \%$ of DOX at pH 7.4 around 12 and 24 h, accordingly, while $47.92 \%$ and $55.1 \%$ were liberated at pH 5.5 at the same time. This is also attributed to the $\mathrm{pH}$-responsive chitin object's ability to alter dose forms over time, as well as the effect of extreme $\mathrm{pH}$ on IRMOF-3 breakdown. Due to $\mathrm{Fe}_{3} \mathrm{O}_{4}$ 's paramagnetic feature, NPs can be employed for magnetic resonance imaging (MRI), indicating that they can be used as a permanent dipole therapeutic agent. Investigators conceived and manufactured a co-delivery, $\mathrm{pH}$-responsive, and highly directed multipurpose medication transporter incorporating DOX/verapamil hydrochloride (VER)@ZIF-8 methoxy polyethylene glycol)-folate (PEG-FA) to improve DOX efficacy.

The DOX carrying capacity of the carrier is $40.9 \%$. Furthermore, while VER works as a P-glycoprotein regulator to eliminate FA's multi-drug sensitivity and specific function in vivo and in vitro, its clinical efficacy is significantly greater than among free DOX as well as other DOX@ZIF-8. Meanwhile, in pH-responsive discharge experiments, DOX and VER exhibited substantial consistent characteristics. A new $\mathrm{Fe}_{3} \mathrm{O}_{4} @ \mathrm{PAA} /$ gold nanoclusters (Ounces)/ZIF-8 system was manufactured by using a simple and gentle technique. It can also help with magnetic resonance imaging (MRI) and X-ray computed tomography (CT), fluorescent quadra scanning, and also have an ultra-high DOX load-bearing capacity. DOX was found to have loading efficiencies of approximately $1.54 \mathrm{~g} / \mathrm{g}$. Moreover, over $68 \%$ of the injected medication has been delivered from the medium during $26.5 \mathrm{~h}$ with $\mathrm{pH}$ 5.3 due to nucleophilic attack of the carboxylic acid groups by DOX and dissolution of 
ZIF-8 compared to only $15 \%$ at $\mathrm{pH} 7.4$ at the same time, showing the double $\mathrm{pH}$-responsive functionality of such a transporter.

Based on in vitro drug release studies, AP-ZIF-90@DOX emitted only 1.7\% DOX at pH 7.4 but $19.8 \%$ once $0.5 \mathrm{mM}$ ATP was introduced. Over $21.7 \%$ DOX also generated within $2 \mathrm{~h}$ with pH 5.0 with $0.5 \mathrm{mM}$ ATP, prompting ZIF-90 to disintegrate under acidity and ATP circumstances. AP-ZIF-90@DOX demonstrated good bioactivity with the animal model after 1 month of in vitro and in vivo mortality studies [102].

In vitro and in vivo mortality experiments demonstrated that $\mathrm{Fe}_{3} \mathrm{O}_{4} @ \mathrm{PAA} / \mathrm{AuNCs} / \mathrm{ZIF}-$ 8 NPs were both nontoxic and anticancer. The multifunctional world features a lot of possibilities for investigations, chemotherapy, and double $\mathrm{pH}$-responsive drug delivery due to the evident portion of the multi-imaging of $\mathrm{Fe}_{3} \mathrm{O}_{4} @ \mathrm{PAA}$ and AuNCs. ZIF-90, which likewise possesses high cell compatibility and $\mathrm{pH}$-responsive drug-release activity, is compensated by zinc ions and imidazole-2-carboxaldehyde (2-ICA). The surface of ZIF-90 was changed by a displacement-based interaction between the aldehyde group of 2-ICA and the amino group of DOX, and 5-FU was subsequently loaded by ZIF-90 to produce a new nanotechnology medicinal carrier [103]. According to medication loaded data, the loading levels of 5-FU and DOX were 36.35 percent and 13.5 percent, respectively. The substance activity of ZIF-90 was also ionic strength sensitive, with 44 percent 5-FU and 20 percent DOX freed in PBS at $\mathrm{pH} 7.4$ after $25 \mathrm{~h}$, while 95 percent and 91 percent of drug release occurred with $\mathrm{pH} 5.5$ after $15 \mathrm{~h}$ and $25 \mathrm{~h}$, respectively. The researchers also created a $\mathrm{pH}$-responsive targeted Nano carrier by combining the Y1 receptor ligands [Asn, 6 Pro34]-NPY (AP) on the interface of ZIF-90 by inserting DOX into ZIF-90 holes. The payload successfully identified and treated triple-negative breast cancer cells.

One-pot wrapping boosted medication availability by roughly 12.6 percent in the loading DOX experiment. Due to the fact that the physical interaction between adenosine triphosphate (ATP) and $\mathrm{Zn}^{2+}$ is substantially stronger than physical bonding between imidazole and $\mathrm{Zn}^{2+}$, AP-ZIF-90-DOX exhibits dual ATP and $\mathrm{pH}$-responsive drug-releasing capabilities.

According to in vitro drug release tests, AP-ZIF-90@DOX released only 1.7 percent DOX at $\mathrm{pH} 7.4$ but released 19.8 percent once $0.5 \mathrm{mM}$ ATP was added. More than 21.7 percent DOX was also produced within $2 \mathrm{~h}$ at $\mathrm{pH} 5.0$ with $0.5 \mathrm{mM}$ ATP, causing ZIF-90 to dissolve under acidic and ATP conditions. After 1 month of in vitro and in vivo mortality investigations, AP-ZIF-90@DOX revealed amazing bioactivity using an animal.

UC@mSiO 2 -RB@ZIF-90-O 2 -DOX-PEGFA (UC = NaYF4:Yb/Er@NaYbF4: Nd@NaGdF4, $\mathrm{RB}=$ Rose Bengal) has also been created as a $\mathrm{pH}$-responsive multifunctional $\mathrm{O}_{2}$-loaded UC@mSiO 2 -RB@ZIF-90-O 2 -DOX-PEGFA (UC = NaYF4: Yb/Er@Na). When exposed to laser light, the core-shell structured UC triggered the photosensitizer (RB) in $\mathrm{mSiO}_{2}$ to generate ROS for PDT. ZIF-90 acts as an oxygen buffer, producing oxygen free radicals that aid in the treatment of malignant hypoxia, improve PDT effectiveness, and demonstrate $\mathrm{pH}$-responsive DOX releasing activity in the tumour. Furthermore, $\mathrm{NH}_{2}$ PEG-modified folic acid (PEGFA) was directly coupled mostly on exterior drug ZIF-90 to improve selective administration and optimise clinical efficiency, and the amount of DOX generated ranged from 79.8 percent to 7.1 percent when the $\mathrm{pH}$ was adjusted from 5.5 to 7.3 after $17 \mathrm{~h}$ within $\mathrm{pH}$-responsive and DOX release investigations. Based on the effective load of $\mathrm{O}_{2}$-loaded PDT and DOX, UC@mSiO $2-\mathrm{RB} @ Z I F-\mathrm{O}_{2}-\mathrm{DOX}-\mathrm{PEGFA}$ showed exceptional anticancer treatment efficacy in in vitro and in vivo studies [104].

\subsection{Design of pH-Responsive/Dependent Drug Carriers}

It is a remarkable achievement to design $\mathrm{pH}$-dependent medicinal carriers in $\mathrm{Zn}$-based MOFs for medical applications. The most commonly used zinc-based MOF for the $\mathrm{pH}$ dependent release of medical drugs is ZIF-8. It has a sodalite (SOD) structure due to its porosity (11.6 $\AA$ ) and sensitivity to acid. Correspondingly, the drug is depicted to have better medicine carrying capacity and $\mathrm{pH}$-dependent release. Moreover, polyacrylicacid@ZIF-8 (commonly known as PAA@ZIF-8) possessed improved DOX loading capacity of $1.9 \mathrm{~g} / \mathrm{g}$. However, this is attributed to electrostatic reactions occurring between positively and nega- 
tively charged DOX and PAA and coordination interaction among $\mathrm{Zn}^{2+}-\mathrm{DOX}$. Therefore, the medication loaded with MOF was found to be released faster into a buffer solution at $\mathrm{pH}$ 5.5 rather than at neutral $\mathrm{pH}$ by confocal laser scanning analyses [105]. Moreover, scientists developed a $\mathrm{pH}$ and temperature-dependent drug release framework with one-dimensional channels from the constituents of zinc ions and bifunctional ligands [106]. For example, framework Zn-TBDA (TBDA $\frac{1}{4} 4^{\prime}$-(1H-tetrazole-5-yl)-[1,1'-biphenyl]-3,5-dicarboxylic acid) showed insignificant cytotoxic activity and depicted an appropriate methotrexate holding potential and controlled release. The dual temperature and $\mathrm{pH}$-responsive release of encapsulated drugs of this complex established its ability as an efficient drug carrier.

Another zinc-based MOF with appropriate size, better BET surface area, and improved density for open free $\mathrm{N}$ sites was prepared with tricarboxylic ligand for the storage and delivery of 5-fluorouracil. This framework showed $\mathrm{pH}$-responsive behavior by releasing $68.6 \%$ of the stored 5-fluorouracil at $6.5 \mathrm{pH}$, further increasing to $86.5 \%$ at $5.0 \mathrm{pH}$ after $24 \mathrm{~h}$. Additionally, the toxicity of this synthesized framework for HepG2 and HFL1 was also measured by MTT assay, which showed satisfactory results.

\section{Medical Applications}

\section{$\mathrm{Zn}$-Based MOF as Drug Carriers}

Many medicinally active ingredients are confined to limited numbers in pharmaceutical applications due to poor stability in living systems, low solubility, and inability to cross natural barriers [2]. Development in the pharmaceutical industry started in the 1970s by introducing drug Nano carriers to improve techniques to prevent the biodegradation of active ingredients, thus protecting the living system from their toxic effects. These techniques improved the effectiveness of the drug by increasing intracellular penetration. Furthermore, Nano techniques have also paved the way for targeting specific tissues, cells, and even cellular organelles [52]. Zinc-based metal-organic frameworks are considered one of the best candidates for developing Nano encapsulates due to their versatility, lower toxicity, and being easily biodegradable.

Different MOFs based on Zn with their encapsulated drug, organic linker, loading degree, and release rate are presented in Table 1. Likewise, a zinc-based MOF was established with bidentate carbene ligand as rigid support that makes it possible for $\mathrm{Zn}-\mathrm{MOF}$ to assist in encapsulating and then discharge the drug (cisplatin). Cisplatin, an effective anticancer medicine, has been verified for its anticancer potential against ovarian cancer cells (A2780) through in vitro trials.

Extremely water-stable (up to 3 weeks), microporous MOF, [Zn8(O)2(CDDB)6(DMF)4(H2O)] where $\mathrm{CDDB}=4,4^{\prime}-(9-\mathrm{H}$ carbazole-3,6-diyl) dibenzoic, was synthesized by a solvothermal process based on an open N-H site, which demonstrated excellent loading potential (around $53.3 \mathrm{wt} . \%$ ) and adequate release potential (64.9 and $81.9 \%$ ) for 5-fluorouracil, and loading capacity is around $53.3 \mathrm{wt} \%$.

An odd 4,8-connected 3D net with (46)2(412•612•84) topology was shown by the coordination polymer. The medication 5 -fluorouracil (5-FU) was connected to the desolated one at around $22.5 \% \mathrm{wt}$. per gram of the dehydrated one. With $92 \%$ of the prescription released after $120 \mathrm{~h}, 5-\mathrm{Fu}$ is discharged in a closely regulated and regular manner. This analysis provides a new method for MOF to be used as possible drug delivery. Compared to zeolites and activated carbons, MOF showed both hydrophilic/hydrophobic entities, and their versatile nature allows porosity to be tailored to physicochemical characteristics. In comparison, structural instability in water has been observed in specific Zn-based metalorganic frameworks. However, to overcome this issue, a biofriendly and water-stable anionic Zn-MOF has been prepared with a dicarboxylic acid as the organic linker.

This medication had a $25 \%$ drug loading weight and $95.6 \%$ removal efficiency after $100 \mathrm{~h}$. The non-toxicity of the synthesized drug has been testified by conducting in vitro MTT assay and in vivo toxicity tests. Drug loading in water $53.3 \%$ by weight and release rate of $81.9 \%$ ) and $64.9 \%$ in PBS was achieved for 5-fluorouracil with negligible cellular toxicity. 


\section{Applications of Zn-Based MOFs for Gases Adsorption, Imaging and Sensors}

Zn-based MOFs have added beneficial aspects in drug delivery as efficient medicinal carriers; they also have other applications. Here, we will summarize the applications of MOFs in various disciplines [107].

\subsection{Zn-Based MOFs for Active Gases Adsorption}

Zn-based MOFs are capable of capturing, separating, storage, and effective delivery of bio medically essential gases. Nitric oxide is an exceptional biomolecule with antibacterial, anti-thrombosis properties and an excellent vasodilating agent [108]. In progressive studies, the capability of $\mathrm{Zn}^{2+}$ exchanged zeolite: polytetrafluoroethylene (50:50) for nitric oxide loading, release, and antibacterial properties was examined. They found better antibacterial activity for nitric oxide-releasing zeolites, whereas nitric oxide-free $\mathrm{Zn}^{2+}$-exchanged zeolite provided excellent potential for fabricating extremely operative dual functionality-bacterial materials, while the application of such nitric oxide donors might include experienced confinement due to the production of certain pro-inflammatory by-products [109].

However, metal-organic frameworks acquire good potential because of their improved storage and control over reaction ability between gas molecules and components of MOF by making appropriate alterations in components. Thus, a Zn-based MOF has been developed by incorporating tetracyanoquindimethane as a linker to create a porous structure for selective absorption of nitric oxide and other gas $\mathrm{CO}_{2}, \mathrm{~N}_{2}, \mathrm{C}_{2} \mathrm{H}_{2}$, and molecules [110]. CPO27 metal-organic frameworks exist in the form of iso-structures formed by the combination of 2-5-dihydroxyterephthalic acid with different metallic parts, including $\mathrm{Mg}, \mathrm{Zn}$, and $\mathrm{Ni}$ [111]. These clusters have pore sizes ranging 11-12 $\AA$ and could be employed to store and release nitric oxide. Furthermore, $\mathrm{Ni}^{2+}$ doped $\mathrm{CPO}-27 \mathrm{Zn}$ ) has been used to strengthen CPO-27 ( $\mathrm{Zn})$ in order to enhance future nitrous oxide release in nitric oxide retention. This composite possessed good thermal stability and the efficient ability to synchronize the solvent molecules, freely subjected to heat to create open sites to capture the nitric oxide [112].

Hydrogen sulfide $\left(\mathrm{H}_{2} \mathrm{~S}\right)$ is also an extremely toxic gas; it could be biologically significant if delivered in a required amount at the desired rate. It has been discovered that metal-organic frameworks with the CPO-27 structure can be used to improve $\mathrm{H}_{2} \mathrm{~S}$ adsorption and preservation. Correspondingly, $\mathrm{H}_{2} \mathrm{~S}$ binding and releasing capacity of $\mathrm{Ni}-\mathrm{CPO}$ and $\mathrm{Zn}-\mathrm{CPO}$ has been testified, demonstrating better nickel delivery (i.e., $1.8 \mathrm{mmol} \cdot \mathrm{g}^{-1}$ from nickel and $0.5 \mathrm{mmol} \cdot \mathrm{g}^{-1}$ from $\mathrm{Zn}$ in $30 \mathrm{~min}$ ) as compared to $\mathrm{Zn}$-based material. However, the ability to deliver less $\mathrm{H}_{2} \mathrm{~S}$ from $\mathrm{Zn}$-based material could be linked with difficulties, such as the incomplete activation of the sample, as earlier reported, or the irreversible and substantial binding potential of zinc to sulfur [113].

\subsection{Zn-MOF as Contrast Agents in MRI}

MOFs have recently been used to replace contrast chemicals in biomedical imaging modalities such as magnetic resonance imaging (MRI). Magnetic resonance imaging (MRI) is widely acknowledged as one of the most prospective imaging methods that do not require ionizing radiation or a radioactive nucleus. Magnetic nanoparticles, on the other hand, can change the MRI signal by speeding up the relaxation phase of protons in nearby $\mathrm{H}_{2} \mathrm{O}$ molecules under an outside magnetic field [114]. Research studies on the fabrication of MOFs as MRI contrast agents have been ongoing since the mid 2000s [115]. The recent developments on Gd III-based nanoscale with good paramagnetic properties have enabled their application as MRI contrast agents.

A versatile framework for magnetized derived medication delivery, MRI agents, and biomedical imaging has also been established using an iron-based MOF nanoscale; two major applications of MOFs include the following: drug carriers for controlled release and the potent contrast agent in MRI image augmentation. ZIF-8 is one of the most extensively studied Nano carriers, emphasizing its application in cancer imaging and treatment. Progressively, glutathione and pH-dependent ZIF-8 were employed to serve as 
platforms for assembling small $\mathrm{Fe}_{3} \mathrm{O}_{4}$ nanoparticles as $\mathrm{T} 1$ contrast agents in the assembly of $\mathrm{Fe}_{3} \mathrm{O}_{4}-\mathrm{ZIF}-8$ acting as a T2 contrasting agent [116]. In vivo investigations used MRI contrast agents with $\mathrm{Fe}_{3} \mathrm{O}_{4}$-based T2-T1 switching for cancer diagnostics. To replace 2-methylimidazolate in ZIF-8 [117], a pH-sensitive 19F MRI Nano probe was created. With a low background and excellent penetration depth, this probe was well suited for stimuliresponsive detection. However, due to their toxicity, these materials are not suited for biotechnology. Nanoparticles have indeed been created for effective delivery systems by combining biosynthetic pathways and scanning features with MOFs. A strong MR-active saturation magnetization micro-MOF linked with folic acid as a fluorescent marker has been efficiently produced that delivers aqueous anticancer medication paclitaxel (Figure 4). These $\mathrm{Fe}_{3} \mathrm{O}_{4} @$ IRMOF-3/FA NPs are a multipurpose spongy framework that could be used for medication administration, bio imaging, and MRI contrast [118].
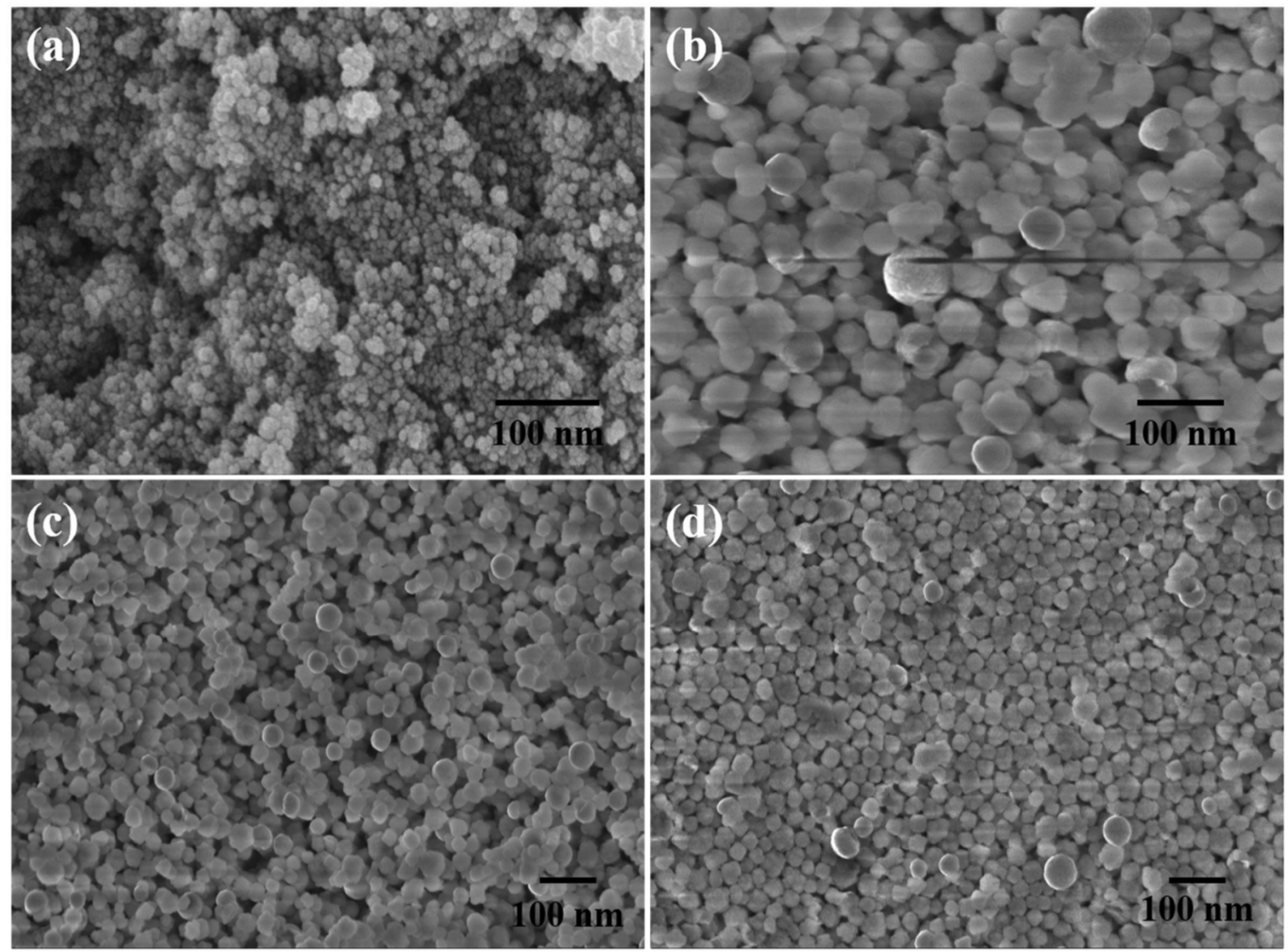

Figure 4. FESEM scans of (a) $\mathrm{Fe}_{3} \mathrm{O}_{4}$ nanoparticles, (b) IRMOF-3, (c) Fe3O4@IRMOF-3, and (d) $\mathrm{Fe}_{3} \mathrm{O}_{4} @$ IRMOF-3/FA [118]. Reprinted with permission from Ref. [118]. Copyright 2016 Royal Society of Chemistry.

However, due to their toxicity, these materials are not suited for biotechnology. Nanoparticles theranostics have indeed been created for effective delivery systems by combining biosynthetic pathways and scanning features with MOFs. A strong MR-active saturation magnetization micro-MOF linked with folic acid as a fluorescent marker has been efficiently produced that can deliver the aqueous anticancer medication paclitaxel. These $\mathrm{Fe}_{3} \mathrm{O}_{4} @ I R M O F-3 / F A$ NPs are a spongy multipurpose framework that could be used for medication administration, bio imaging, and MRI contrast. Regarding cancerous cells, concatenated folic acid demonstrated a greater T2-weighted MRI distinction. ZIF-8, a more investigated nanoparticles that has been employed in clinical therapy and diagnosis, is a much more investigated nanoparticle. Small $\mathrm{Fe}_{3} \mathrm{O}_{4} \mathrm{NPs}$ (T1 distinction agent) have indeed been produced together into $\mathrm{T} 2$ contrast material $\mathrm{Fe}_{3} \mathrm{O}_{4}-\mathrm{ZIF}-8$ architecture that used a pH 
and glutathione-responsive ZIF-8 as both structures. For in vivo diagnostic procedures, an $\mathrm{Fe}_{3} \mathrm{O}_{4}$-based precise $\mathrm{T} 2-\mathrm{T} 1$ switching image reconstruction approach is particularly successful. Since $1 \mathrm{H}$ MRI has a low exposure, the number of protons in human tissue causes strong background signals.

\subsection{Nanoscale Metal-Organic Framework for Ultrasonographic Scanning}

Nanoscale MOFs have been investigated for their possible use in a variety of applications such as X-ray computed tomography imaging (CT imaging) as contrast agents with the addition of high atomic number elements as their building blocks [119]. Meanwhile, $\mathrm{Cu}^{2+}$ and $\mathrm{Zn}^{2+}$ were employed as metal parts along with 2,3,4,5,6-tetraiodo-1,4benzenedicarboxylate (I4-BDC) as bridging ligands for the fabrication of iodinated nanoscale metal-organic frameworks [Cu(I4-BDC) $\left.\left(\mathrm{H}_{2} \mathrm{O}\right) 2\right] \cdot 2 \mathrm{H}_{2} \mathrm{O}$ and $[\mathrm{Zn}(\mathrm{I} 4-\mathrm{BDC})-(\mathrm{EtOH}) 2] \cdot 2 \mathrm{EtOH}$, respectively. These fabricated MOFs contained a high level of $63 \%$ of iodine weight. In contrast, phantom studies verified that X-ray attenuation coefficients of these MOFs are analogous to the conventionally used molecular contrast agent such as iodixanol. Therefore, it can be concluded that these frameworks provided a unique platform for devising efficient contrast agents that could be used in CTI by incorporating iodinated compounds as bridging ligands [120].

\subsection{Chemosensors Composed of Zn-Based MOFs}

There has been extensive research being conducted regarding applications of biosensors for detection and quantification of certain compounds. Biosensor is a term used to define a device with sensing elements of biological origin, which is linked to or assimilated within a transducer [121,122].

Metal organic frameworks that are constituted by assembling metal and organic linkers have been studied broadly as chemical sensors. The most imperative characteristic of these MOFs is their inherent luminescence that make possible their application as sensors. In recent times, nanomaterials have been broadly investigated as bio or chemo sensors with improved selectivity, sensitivity, and response time because of their certain chemical properties attributed to particular host-guest interaction [123]. Zinc based MOFs might be transduced into a device because of their luminescent characteristics and, hence, act as chemical sensors; therefore, they are favorable ligand for the synthesis of Zn-MOFs having nucleophilic attributes in effective luminescent sensors and could be electron-rich' p-conjugated fluorescent compounds [124]. In addition, the organic linkers in such MOFs are possible to fabricate on the basis of their potentials in oxidative quenching. Luminescent lanthanide cations, which emit in NIR and visible regions, were introduced into the bioMOF-1 pores for biomedical applications [125] (Figure 5). This inflexible anionic porous framework $\left(1700 \mathrm{~m}^{2} / \mathrm{g}\right)$ can be utilized as a photostable $\mathrm{O}_{2}$ sensor. In another study, temperature and luminescent sensors were successfully deliberated by employing [2,4,6tris(3,5-dicarboxyl phenylamino)-1,3,5-triazine] as an organic linker in MOFs with Zn as metal. An in situ doping approach can be applied for achieving MOFs with magnetic and fluorescence attributes. In this approach, Rexit created a heptanuclear zinc cluster-based MOF with luminescence using a polycarboxylate ligand containing trifluoromethyl groups. Temperature and luminescence sensors were effectively developed in another work by using [2,4,6-tris(3,5-dicarboxylphenylamino)-1,3,5-triazine] as an organic linker in MOFs with $\mathrm{Zn}$ as the metal [126]. 


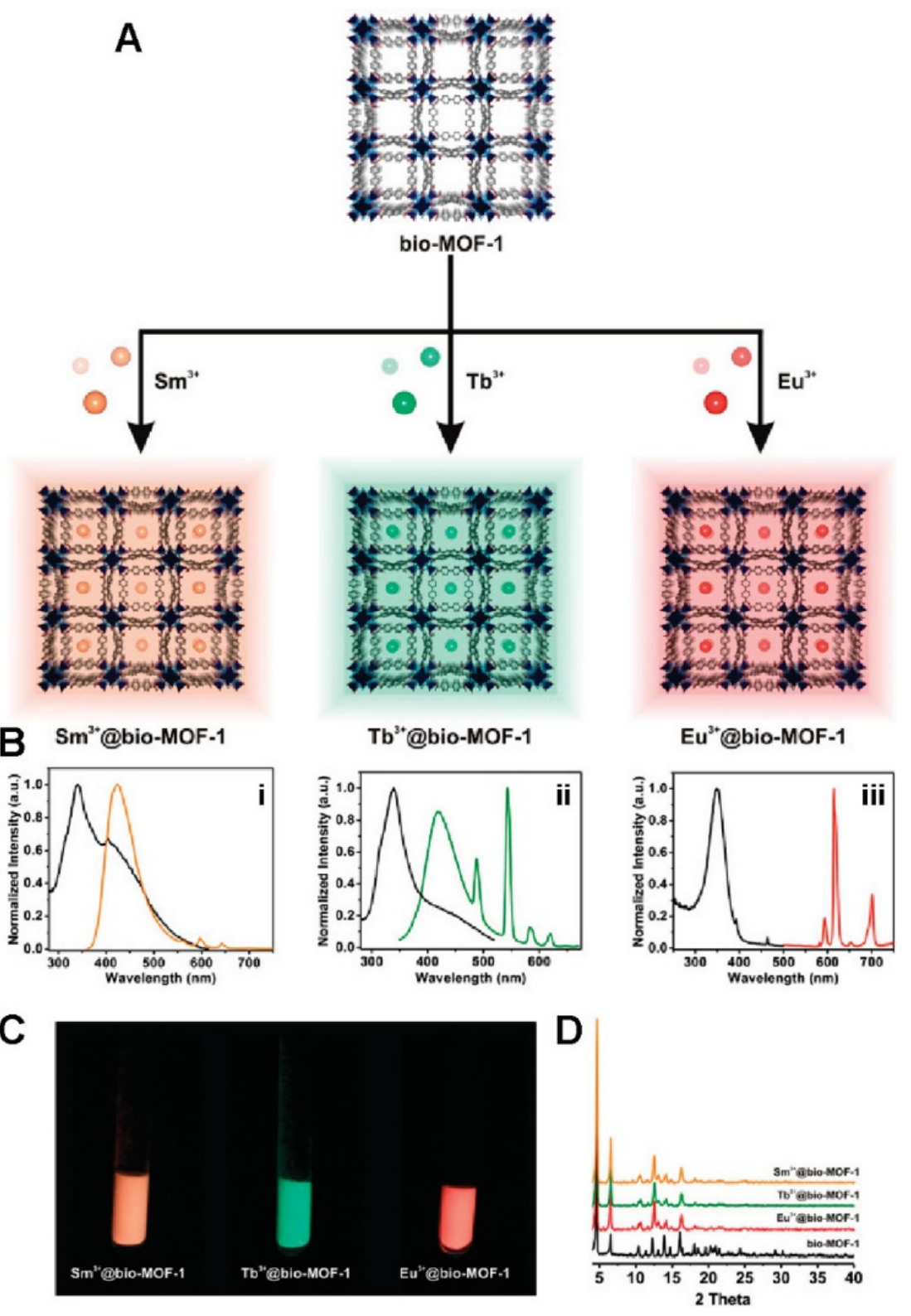

Figure 5. (A) Bio-MOF-1 encapsulation and sensing of lanthanide cations and (B) Bio-MOF-1 with transition metals cations: absorption and emission spectra of $\mathrm{Sm}^{3+} @$ bio-MOF-1 (i), Tb ${ }^{3+} @$ bio-MOF-1 (ii), and Eu ${ }^{3+} @$ bio-MOF-1 (iii). (C) Samples of Ln ${ }^{3+} @$ bio-MOF-1 with transition metals cations illuminated with 365 nm UV light. (D) XRPD patterns of Ln ${ }^{3+} @$ bio-MOF-1. Reprinted with permission from Ref. [125]. Copyright 2011 American Chemical Society.

The glycopeptides of human blood $(1 \mathrm{~L})$ were enriched after incubation with the MG@Zn-MOFs, followed by elution, deglycosylation, and independent analysis using nano-LC-MS/MS. Surprisingly, 517 distinct N glycopeptides and 151 distinct glycoproteins may be effectively identified. Magnetic graphene hydrophilic porous bio composite (MG@Zn-MOFs) functionalized with metal-organic frameworks (MOFs) for glycopeptide recognition. MG@Zn-MOFs demonstrated great sensitivity and selectivity, as well as high recyclability, in glycopeptides analysis due to their strong magnetic responsiveness, large specific surface area, superior biocompatibility and unique size-exclusion effect. In practice, $517 \mathrm{~N}$-glycopeptides among 151 distinct glycoproteins were definitely identified from human serum $(1 \mathrm{~L})$ treated with the MG@Zn-MOFs, which is the best result among published results so far. The MG@Zn-MOFs biocomposite outperforms the individual magnetic graphene and Zn-MOFs counterparts in glycopeptide selectivity. Furthermore, the de- 
veloped biocomposite exhibits remarkable results for glycopeptide enrichment in human blood (1 L), demonstrating its potential use in practical applications. The MG@Zn-MOFs biocomposite combines the benefits of magnetic graphene and $\mathrm{Zn}-\mathrm{MOF}$, including a large number of affinity sites, a unique aperture-screen effect, great magnetic responsiveness, and a high specific surface area. Graphene-based materials have also been employed in the enrichment of glycopeptides. Wang et al. developed an MOF-functionalized magnetic graphene nanoporous composite (C-magG@ZIF-8) that demonstrated high selectivity, sensitivity, and repeatability. MOFs are synthesized using a crystal assemble growth technique by grafting Zn-MOF onto magnetic graphene sheets, resulting in homogeneous coating. The major properties include a large surface area, high stability, and an improved sizeexclusion effect. Using this affinity material, $517 \mathrm{~N}$-glycosylation sites in human blood are found, which is the most so far in glycoproteome study $[127,128]$.

Saleem, Shafaq, and colleagues created a hydrophilic terpolymer MOF composite with a large surface area and porosity to enrich mono-glycosylated and multi-glycosylated peptides, allowing for a bottom-up approach. Terpolymer@ZIF-8 is created by using free radical polymerization and layer-by-layer ZIF-8 manufacture. Aminophenylboronic acid was then used to modify the surface (AMBA). After exposing enriched and PNGase-treated deglycosylated peptides to LC-MS, 318 N-linked glycopeptides were discovered from $1 \mathrm{~L}$ human serum digest. As a result, terpolymer@ZIF-8@BA has the capacity to produce monoglycosylated and multi-glycosylated peptides from complicated biological samples [129].

Sawayama, Taku, and colleagues discovered that metal-organic frameworks (MOFs) can distinguish topological designs of macromolecules, such as linear and cyclic structures, by selective polymer insertion into nanopores. They described a novel polymer separation technology that use metal-organic frameworks (MOFs) to distinguish between linear and cyclic polyethylene glycols (PEGs) by selective polymer insertion into the MOF nanopores. Analytical and preparative chromatographic separations of these topologically different pairings ere made possible by the preparation of an MOF-packed column. Furthermore, utilizing MOF as an adsorbent, gram-scale PEGs with solely cyclic structures were effectively produced from a crude reaction mixture. Oe and Noriyoshi et al. revealed that polymer insertion into sub-nanoporous MOFs happens spontaneously from the solution phase [130]. When the system achieves sufficient enthalpy to overcome potential entropic losses owing to uncoiling of the solvated polymer chains, admission of polymer chains that assume coiled and self-entangled conformations with exceptionally higher hydrodynamic diameters relative to the pore diameter is achievable. PEGs were used to explore the thermodynamics and kinetics of polymer insertion, which revealed an enthalpy-driven mechanism coupled with a dynamic insertion/rejection process at the solution/MOF interface. Isothermal adsorption study indicated a unique solvent dependency of PEG insertion, which is explained by PEG-MOF affinity, MOF-solvent affinity, and the solvation effect [131].

We proved the significant potential of MOFs for the separation of polymers that vary only in their terminal groups, in addition to their utility for the separation of gases and small molecules. In this method, polymer chains are inserted into MOFs through their extremities, allowing for the separation of functionalized PEG with diverse terminal groups of varying natures and sizes. It was interesting to see how MOFs with stiff pores could distinguish the terminal groups of PEG based on steric hindrance. Furthermore, we could take use of the dynamic nature of flexible MOFs to precisely recognize terminal groups of comparable size but slightly different polarity. These two separation modes, which are critical for the separation of tiny molecules by MOFs, retain their capacity to distinguish terminal groups even when they are connected to lengthy polymer chains in this case. Thus, the utilization of MOFs may be at the heart of a highly wanted technology for the robust and systematic separation of polymers, particularly PEG, for which their pervasive usage in biology necessitates the use of very pure materials. Due to the diversity of MOFs, our technique may be expanded to a broad range of polymer separations, offering up interesting possibilities for highly adaptable polymer purification systems [132]. 
Furthermore, the organic linkers in MOFs can be customized via the oxidative quenching method. For sensing nitro aromatics, particularly trinitrophenol (TNP), zinc-based luminous MOFs were synthesized using a flexible electron-rich N-involved linker [133]. Photo-excitation power is transported from the linker to the cations TNP when anion MOFs engage with TNP, resulting in luminescence quenching. The in situ doping method may account for both magnetic and fluorescence characteristics.

This was demonstrated by synthesizing a heptanuclearzinc cluster-based MOF with luminescence properties based on a polycarboxylate ligand containing trifluoromethyl groups. Poorer fluorescence characteristics are observed in the $\mathrm{Co}^{2+}$-doped $\mathrm{Zn}^{2+}-\mathrm{MO}$. In another place, TDPAT [2,4,6-tris(3,5-dicarboxyl phenyl amino)-1,3,5-triazine] has been used as a bridge for $\mathrm{Zn}$-based MOFs to build an effective fluorescence or temperature monitoring agent (Figure 6a,b) [126].
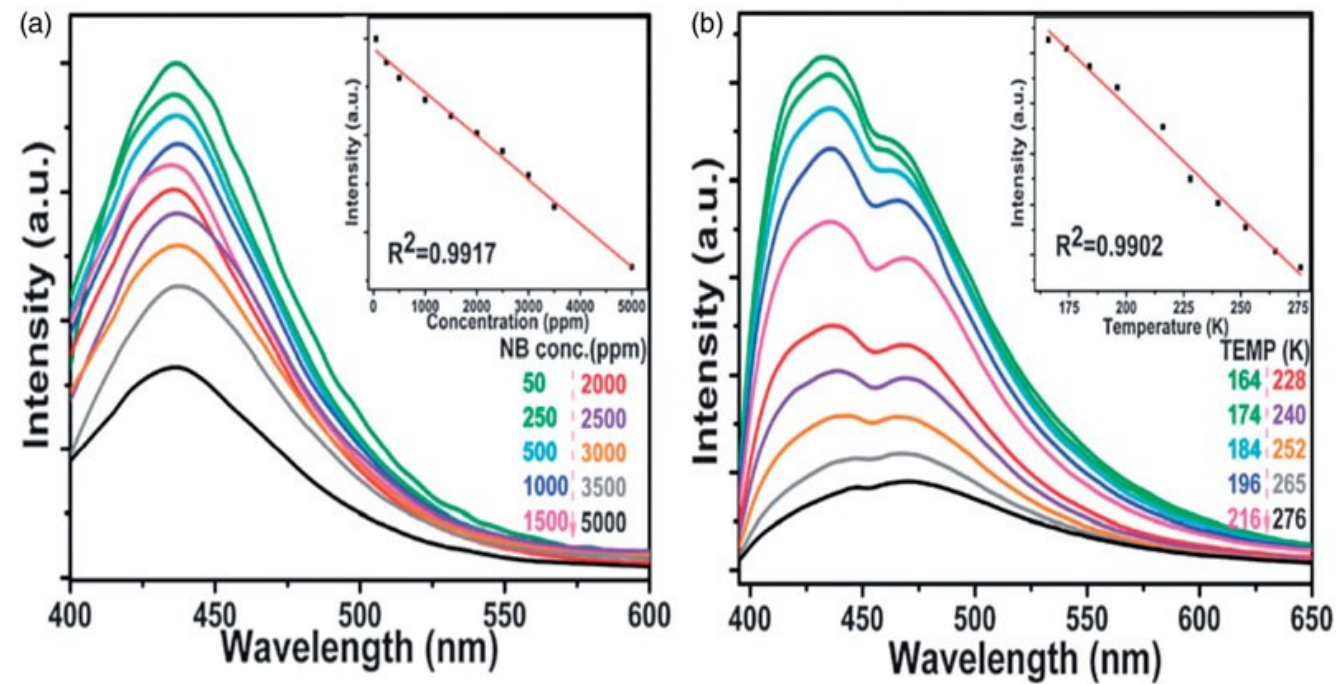

Figure 6. (a) Zn-TDPAT emission spectra (kex at lower wavelength) at varied concentration levels and (b) various thermal values [131]. Reprinted with the permission of Ref. [126]. Copyright 2013 Royal Society of Chemistry.

\subsection{MOFs for Antigens and Adjuvants}

Due to the fact that antigens have limited immunogenicity and little binding ability to the target, using them as vaccines on their own typically results in modest immune responses [134]. Due to their great loading capacity, nMOFs may assist antigens in directly targeting the immune response. These compounds are varied in composition and structure and are readily adjustable, making it easier to make nMOFs with desired forms, sizes, and chemical characteristics for any sort of targeting, including lymph node [135-137]. ZIF-8's imidazole was protonated inside acidic lysosomes, changing its interaction with zinc ions and enabling OVA to escape from lysosomes into the cytoplasm and be cross-presented by dendritic cells (DCs), as well as a larger percentage of CD8+ T cells secreting IFN-+ and IgG2a antibody. The OVA and CpG combination produced less secretion than the nanoparticles. In mice carrying EG7-OVA cells (EL-4 thymoma tumour cells transfected with the OVA gene), CpG/ZANPs dramatically decreased tumour development and extended life, demonstrating increased antigen-specific CTL response.

Based on these findings, nMOFs have the following advantages: (i) extremely high antigen loading capacity; (ii) nMOFs can subsequently enhance antigen immunogenicity and uptake by APCs; (iii) nMOFs degraded in acidic endo/lysosomes enable the release of encapsulated antigens into the cytoplasm, resulting in enhanced antigen cross-presentation ability; and (iv) compatibility. 


\section{Problems Associated with Current Zn-MOFs}

The utility of $\mathrm{Zn}-\mathrm{MOF}$ in medical treatments is hampered by various factors. However, these factors are not unsolvable but could be a barrier for actively progressing scientific inventions. However, some of the essential elements contributing primarily to the limitations of Zn-MOFs application are summarized with their possible remedies in the following sections.

\subsection{Stability}

Various factors such as host-guest interaction, toxicity, porosity, hydrophilic, and hydrophobic ratios are responsible for implementing MOFs. Nevertheless, performance in the applied system intensely depends on their biodegradable characteristics. However, the framework is based on the bonding forces between metallic and organic ligand parts. An uninterrupted ligand interchange phenomenon is expected from the complexing group to the water molecule from the metal and vice versa. Therefore, while working with MOFs in biological systems with diverse composition ranges and $\mathrm{pH}$, it is imperative to look for the stability of these frameworks, which impact their activity, while stability measurements could be carried out by exposing MOFs to different conditions that are very much similar to the biological ones such as phosphate buffer solution, simulated body fluids, and water, followed by determination of any defect in the MOFs structure without any significant degradation [138]. At the same time, the instability of MOFs structure in the presence of water may reduce their activity by affecting their pores volume and internal surface.

Various research studies reported that MOF-5, also known as zinc terephthalate, is extremely unstable in water. In further studies, MOFs based on Zn metal is reticular MOF-1, known as IRMOF-1, having a porous cubical structure that showed appropriate stability up to $450{ }^{\circ} \mathrm{C}$ in the presence of nitrogen [139]. It suffers irreparable structural degradation in the presence of atmospheric moisture [140]. Nitrogen bases containing MOFs with organic linkers and zinc as metal parts have improved stability compared to those constituted from irreparable structural degradation [141].

The problem can be addressed by applying different strategies for improving the stability of the MOFs such as functionalization and selection of appropriate composition and structure. Thus, a significant factor to be well thought-out in application of MOFs is modification in their surface and control over distribution of particle size. Not only can the stability of MOFs be enhanced by such surface alterations but also drug carrying procedure through diverse physiological barriers [24].

In the recent times, researchers have paid attention to the modification of MOFs for improving their stability and, in this regard, the development of nano MOFs or alterations in MOFs with metals in the form of nanoparticles is an important milestone. The activity of such MOFs is dependent upon properties of nanoparticles and the particular type of linkers. An example of a nanoparticle-based MOF is the ZIF-8 with particles of controlled size. Poly (ethylene glycol) (PEG) surface modification has been employed to control the particle size of ZIF- 8 by using PEG as a capping agent. These MOFs revealed $\mathrm{pH}$ dependent drug release efficacy against cancer cells.

Modification in the structure of MOFs could be performed according to the required application type by dispersing MOFs particles inside their matrix or could be accomplished by forming composites in core-shell [142]. Core-shell composite, i.e., IRMOF-2@MOF-5 can carry the load and could be the potential host for guest compounds [143]. Another modification in MOFs is the use of bimetallic MOFs, which exhibit improved framework stability as compared to their single parent MOFs [49]. An example of such MOFs is the development of ZnZr-based bimetallic MOFs by using MOF-on-MOF techniques, and it was testified as aptasensor scaffolds for sensing cancer marker protein tyrosine kinase-7 (PTK7). These complexes were formulated by altering various orders of metal precursors as well as ligands. The improved activity in bimetallic MOFs is achieved as Zr-MOFs assist aptamer immobilization, while the Zn-based MOF caused the stabilization of the G-quadruplex formed by aptamer strands and PTK7 [144,145]. 


\subsection{Toxicity Studies}

The wide range of available components for the design of MOFs may allow finding the appropriate one with toxicological acceptability. MOFs that are based on linkers from endogenous sources and metals are limited as compared to general MOFs [99]. In toxicological assessments, complete composition of MOFs must be subjected to different assays to assess the incidence of any toxic molecule (i.e., ligand or metal) in their structure. In this regard, the application of porous MOFs for biomedical application will require preliminary toxicological assessment trails for each of the components [24]. Zn, among others toxic and abundantly used metal, is comparatively safe in biological functions and, hence, considered suitable for theranostic applications. The studies related to the toxicity and stability of various Zn-based metal organic frameworks conducted with different human cell lines and various in vitro assays are presented in Table 2, which include estimating the cytotoxicity of one of the Zn-based MOF, i.e., nanoZIF-8 for three human cell lines such as H292, HT-29, and HL-60. It was concluded that nanoZIF-8 poses no cytotoxicity to any of the above-mentioned cells at $109 \mathrm{~mm}$ (IC50) [146,147].

Table 2. Stability and toxicity associated with various Zn-based metal organic frameworks.

\begin{tabular}{|c|c|c|c|c|c|}
\hline \multirow{2}{*}{ Zn-MOFs } & \multirow{2}{*}{$\begin{array}{l}\text { Stability } \\
\text { Studies }\end{array}$} & \multicolumn{2}{|c|}{ Toxicity } & \multirow{2}{*}{$\begin{array}{l}\text { Mechanism of } \\
\text { Toxicity }\end{array}$} & \multirow{2}{*}{ Reference } \\
\hline & & Cell Lines & IC50 & & \\
\hline nanoZIF-8 & - & $\begin{array}{l}\text { HeLA } \\
\text { J774 }\end{array}$ & $\begin{array}{l}436 \mathrm{~mm} \\
109 \mathrm{~mm}\end{array}$ & $\begin{array}{l}\text { Breakdown of } \\
\text { frameork into its } \\
\text { constituents } \\
\text { in the cell } \\
\text { and endosomal } \\
\text { environment }\end{array}$ & [147] \\
\hline IRMOF-3 & $\begin{array}{c}\text { Stable at a } \\
\text { temperature of } \\
450^{\circ} \mathrm{C} \text { in the } \\
\text { presence of } \mathrm{N}_{2} \text { gas }\end{array}$ & PC12 & $\begin{array}{c}\text { Negligible at } \\
(25 \mathrm{~g} / \mathrm{mL}) \\
\text { Considerable at } \\
(100 \mathrm{~g} / \mathrm{mL})\end{array}$ & $\begin{array}{c}\text { Disruption of } \\
\text { cellular zinc } \\
\text { homeostasis and } \\
\text { down-regulation } \\
\text { of GAP-43 protein }\end{array}$ & [92] \\
\hline Nano ZIF-8 & $\begin{array}{c}\text { Stable at a } \\
\text { temperature of } 55^{\circ} \mathrm{C} \\
\text { in the presence of } \mathrm{N}_{2} \\
\text { gas and in PBS } \\
\text { (pH 7.4) for } 7 \text { days } \\
\text { Stable in water }\end{array}$ & $\begin{array}{l}\text { NCI-H292 } \\
\text { HT-29 } \\
\text { HL-60 }\end{array}$ & $>25 \mathrm{mg} / \mathrm{mL}$ & $\begin{array}{l}\text { Less cytotoxicity of } \\
\text { ZIF- } 8 \text { is linked } \\
\text { with the gentle } \\
\text { release of drug }\end{array}$ & [146] \\
\hline CS/Bio-MOF & Stable in PBS & MCF-7 & $3.1251 \mathrm{~g} / \mathrm{mL}$ & - & [143] \\
\hline ZIF-7 & $\begin{array}{l}\text { Stable in fetal bovine } \\
\text { serum }(10 \%)\end{array}$ & MCF-7 & Moderate toxicity & $\begin{array}{l}\text { Slow release of } \\
\text { drug }\end{array}$ & [148] \\
\hline Zn-MOF-74 & $\begin{array}{l}\text { Stable in fetal bovine } \\
\text { serum }(10 \%)\end{array}$ & $\begin{array}{l}\text { HepG2 } \\
\text { MCF7 }\end{array}$ & High Toxicity & $\begin{array}{c}\text { Viability } \\
38.8 \pm 3.6 \% \text { at } \\
200 \mathrm{mM} \\
\text { Viability } \\
57.6 \pm 0.6 \% \text { at } \\
200 \mathrm{mM}\end{array}$ & [149] \\
\hline
\end{tabular}

\section{Conclusions}

Current data about development and applications of MOFs are quickly proliferating in recent years, but there is still a noteworthy gap in the complete understanding of their structure, properties, and stability under different conditions. There is room to investigate in-depth mechanisms responsible for the destruction of crystalline structure of these MOFs. In areas of biomedical applications, most commonly used drugs are mainly composed of anticancer and antiviral molecules. Such applications can be further broadened to carry drugs against other disorders as well. A comprehensive in vitro and 
in vivo toxicity assessment is mandatory for commercialization of such products. Another advancement in the development of MOFs is the creation of bio-MOFs from constituents such as biocompatible metals and activated pharmaceutical ingredients (APIs) followed by their degradation within physiological surroundings that allow for the gradual release of loaded drugs like that of encapsulated APIs within the pores of traditional MOFs. Both methods can be combined as well for codelivery of the drug to the targeted site either as a component of framework or encapsulated within pores. In the future, MOFs can also be tested for the delivery of larger, complex biomolecules such as hormones [150,151].

In vivo studies to investigate the stability, degradation, and processes of MOFs are currently missing. Although there is a review article on the uses of Zn-based MOF in drug delivery and cell imaging, most of the Zinc-based metal-organic frameworks as nontoxic and biodegradable platforms for biomedical applications are yet unknown. However, to our knowledge, no recent review paper focusing on the applications and synthesis of $\mathrm{Zn}$-based MOF has been published. As a result, a review of the many uses of various $\mathrm{Zn}$-based MOF with various linkers is required to provide a critical assessment of the data available from previous studies as well as to identify gaps for future study. This study aims to provide the most up-to-date information on the uses of various Zn-based MOFs. Furthermore, the review discusses toxicity, stability, and effects of $\mathrm{pH}$ on the application of MOFs, as well as the efficacy of different Zn-based MOFs for drug delivery and cell imaging, as well as the challenges and evidence gaps that arise when using different linkers to make the application of MOF more effective, as well as suggesting knowledge gaps to researchers for future studies [152]. Various studies using multimodal imaging methods have been carried out to monitor the degrading routes of MOFs, but further research is needed to fully understand the process. This cleared the door for further research into MOF routes in the future. In this context, the long-term absorption-distribution-metabolism-excretion pathway must be carefully monitored to assess the accumulation of MOFs in various tissues due to the diverse modes of administration. Scale-up development is still a barrier to mass manufacturing for this innovative family of porous crystalline materials. As a result, the world of MOFs has to be further researched in order to attain cost efficiency and improved performance, as well as high purity and yield of nanostructures.

Author Contributions: Conceptualization, R.S.A.; H.M.; writing-original draft preparation, R.S.A.; writing-review and editing, H.M.; Z.L.; project administration, H.M.; Z.L.; funding acquisition, H.M.; Z.L. All authors have read and agreed to the published version of the manuscript.

Funding: This research was funded by National Natural Science Foundation of China grant number [21974125 and 21605038].

Acknowledgments: Authors thank the National Natural Science Foundation of China (21974125 and 21605038) for financial support.

Conflicts of Interest: The authors declare no conflict of interest.

\section{References}

1. Cai, G.; Yan, P.; Zhang, L.; Zhou, H.-C.; Jiang, H.-L. Metal-Organic Framework-Based Hierarchically Porous Materials: Synthesis and Applications. Chem. Rev. 2021, 121, 12278-12326. [CrossRef] [PubMed]

2. Chen, Z.; Li, X.; Yang, C.; Cheng, K.; Tan, T.; Lv, Y.; Liu, Y. Hybrid Porous Crystalline Materials from Metal Organic Frameworks and Covalent Organic Frameworks. Adv. Sci. 2021, 8, 2101883. [CrossRef] [PubMed]

3. Yin, Z.; Zhou, Y.-L.; Zeng, M.-H.; Kurmoo, M. The concept of mixed organic ligands in metal-organic frameworks: Design, tuning and functions. Dalton Trans. 2015, 44, 5258-5275. [CrossRef]

4. Seoane, B.; Coronas, J.; Gascon, I.; Benavides, M.E.; Karvan, O.; Caro, J.; Kapteijn, F.; Gascon, J. Metal-organic framework based mixed matrix membranes: A solution for highly efficient $\mathrm{CO}_{2}$ capture? Chem. Soc. Rev. 2015, 44, 2421-2454. [CrossRef] [PubMed]

5. Batten, S.R.; Champness, N.R.; Chen, X.-M.; Garcia-Martinez, J.; Kitagawa, S.; Öhrström, L.; O'Keeffe, M.; Suh, M.P.; Reedijk, J.J.P. Terminology of metal-organic frameworks and coordination polymers (IUPAC Recommendations 2013). Pure Appl. Chem. 2013, 85, 1715-1724. [CrossRef]

6. Baumann, A.E.; Burns, D.A.; Liu, B.; Thoi, V.S. Metal-organic framework functionalization and design strategies for advanced electrochemical energy storage devices. Commun. Chem. 2019, 2, 1-14. [CrossRef] 
7. Wyszogrodzka, G.; Dorożyński, P.; Gil, B.; Roth, W.J.; Strzempek, M.; Marszałek, B.; Weglarz, W.P.; Menaszek, E.; Strzempek, W.; Kulinowski, P.J. Iron-based metal-organic frameworks as a theranostic carrier for local tuberculosis thera-py. Pharm. Res. 2018, 35, 1-11. [CrossRef]

8. Deng, K.; Hou, Z.; Li, X.; Li, C.; Zhang, Y.; Deng, X.; Cheng, Z.; Lin, J. Aptamer-Mediated Up-conversion Core/MOF Shell Nanocomposites for Targeted Drug Delivery and Cell Imaging. Sci. Rep. 2015, 5, srep07851. [CrossRef]

9. Cai, M.; Chen, G.; Qin, L.; Qu, C.; Dong, X.; Ni, J.; Yin, X. Metal Organic Frameworks as Drug Targeting Delivery Vehicles in the Treatment of Cancer. Pharmaceutics 2020, 12, 232. [CrossRef]

10. Bilal, M.; Adeel, M.; Rasheed, T.; Iqbal, H.M. Multifunctional metal-organic frameworks-based bio-catalytic platforms: Recent developments and future prospects. J. Mater. Res. Technol. 2019, 8, 2359-2371. [CrossRef]

11. Tibbetts, I.; Kostakis, G.E. Recent Bio-Advances in Metal-Organic Frameworks. Molecules 2020, 25, 1291. [CrossRef]

12. Horcajada, P.; Chalati, T.; Serre, C.; Gillet, B.; Sébrié, C.; Baati, T.; Eubank, J.F.; Heurtaux, D.; Clayette, P.; Kreuz, C.; et al. Porous metal-organic-framework nanoscale carriers as a potential platform for drug delivery and imaging. Nat. Mater. 2010, 9, 172-178. [CrossRef]

13. Imaz, I.; Rubio-Martínez, M.; An, J.; Sole-Font, I.; Rosi, N.L.; Maspoch, D.J. Metal-biomolecule frameworks (MBioFs). Chem. Commun. 2011, 47, 7287-7302. [CrossRef]

14. Sun, Y.; Zheng, L.; Yang, Y.; Qian, X.; Fu, T.; Li, X.; Yang, Z.; Yan, H.; Cui, C.; Tan, W.J. Metal-organic framework nanocarri-ers for drug delivery in biomedical applications. Nano Micro Lett. 2020, 12, 1-29. [CrossRef]

15. Rojas, S.; Devic, T.; Horcajada, P. Metal organic frameworks based on bioactive components. J. Mater. Chem. B 2017, 5, 2560-2573. [CrossRef]

16. Li, Z.; Fraile, J.; Viñas, C.; Teixidor, F.; Planas, J.G.J. Post-synthetic modification of a highly flexible 3D soft porous metal-organic framework by incorporating conducting polypyrrole: Enhanced MOF stability and capacitance as an electrode material. Chem. Commun. 2021, 57, 2523-2526. [CrossRef] [PubMed]

17. Kalaj, M.; Cohen, S.M. Postsynthetic modification: An enabling technology for the advancement of metal-organic frame-works ACS Central Sci. 2020, 6, 1046-1057. [CrossRef]

18. Lv, M.; Zhou, W.; Tavakoli, H.; Bautista, C.; Xia, J.; Wang, Z.; Li, X. Aptamer-functionalized metal-organic frameworks (MOFs) for biosensing. Biosens. Bioelectron. 2021, 176, 112947. [CrossRef] [PubMed]

19. Cai, W.; Chu, C.-C.; Liu, G.; Wáng, Y.-X.J. Metal-Organic Framework-Based Nanomedicine Platforms for Drug Delivery and Molecular Imaging. Small 2015, 11, 4806-4822. [CrossRef] [PubMed]

20. Kreno, L.E.; Leong, K.; Farha, O.K.; Allendorf, M.; Van Duyne, R.P.; Hupp, J.T. Metal-Organic Framework Materials as Chemical Sensors. Chem. Rev. 2012, 112, 1105-1125. [CrossRef]

21. Zhu, Q.-L.; Xu, Q.J. Metal-organic framework composites. Chem. Soc. Rev. 2014, 43, 5468-5512. [CrossRef] [PubMed]

22. Fudouzi, H. Colloidal Photonic Crystal Films: Fabrication and Tunable Structural Color and Applications. In Energy Options Impact on Regionanomatl Securials and Nanoarchitecturesy; Springer: Singapore, 2015; pp. 1-19.

23. Horcajada, P.; Gref, R.; Baati, T.; Allan, P.K.; Maurin, G.; Couvreur, P.; Ferey, G.; Morris, R.E.; Serre, C.J. Metal-organic frameworks in biomedicine. Chem. Rev. 2012, 112, 1232-1268. [CrossRef]

24. Cunha, D.; Ben Yahia, M.; Hall, S.; Miller, S.R.; Chevreau, H.; Elkaïm, E.; Maurin, G.; Horcajada, P.; Serre, C. Rationale of Drug Encapsulation and Release from Biocompatible Porous Metal-Organic Frameworks. Chem. Mater. 2013, 25, 2767-2776. [CrossRef]

25. Liu, W.-L.; Lo, S.-H.; Singco, B.; Yang, C.-C.; Huang, H.-Y.; Lin, C.-H. Novel trypsin-FITC@MOF bioreactor efficiently catalyzes protein digestion. J. Mater. Chem. B 2013, 1, 928-932. [CrossRef]

26. Zhang, H.; Liu, D.; Yao, Y.; Zhang, B.; Lin, Y. Stability of ZIF-8 membranes and crystalline powders in water at room tem-perature. J. Membr. Sci. 2015, 485, 103-111. [CrossRef]

27. Lee, Y.J.; Yeon, C.; Lim, J.W.; Yun, S.J.J. Flexible p-type PEDOT: PSS/a-Si: H hybrid thin film solar cells with boron-doped interlayer. Sol. Energy 2018, 163, 398-404. [CrossRef]

28. Bahrani, S.; Hashemi, S.A.; Mousavi, S.M.; Azhdari, R. Zinc-based metal-organic frameworks as nontoxic and biodegrada-ble platforms for biomedical applications: Review study. Drug Metab. Rev. 2019, 51, 356-377. [CrossRef] [PubMed]

29. Purnamawati, S.; Indrastuti, N.; Danarti, R.; Saefudin, T. The Role of Moisturizers in Addressing Various Kinds of Dermatitis: A Review. Clin. Med. Res. 2017, 15, 75-87. [CrossRef]

30. Gupta, M.; Mahajan, V.K.; Mehta, K.S.; Chauhan, P.S. Zinc Therapy in Dermatology: A Review. Dermatol. Res. Pract. 2014, 2014, 709152. [CrossRef]

31. McKinlay, A.C.; Morris, R.E.; Horcajada, P.; Férey, G.; Gref, R.; Couvreur, P.; Serre, C. BioMOFs: Metal-Organic Frameworks for Biological and Medical Applications. Angew. Chem. Int. Ed. 2010, 49, 6260-6266. [CrossRef] [PubMed]

32. Chowdhury, M.A. The applications of metal-organic-frameworks in controlled release of drugs. Rev. J. Chem. 2017, 7, 1-22. [CrossRef]

33. Yang, J.; Yang, Y. Metal-Organic Frameworks for Biomedical Applications. Small 2020, 16, e1906846. [CrossRef] [PubMed]

34. Howarth, A.J.; Liu, Y.; Li, P.; Li, Z.; Wang, T.C.; Hupp, J.T.; Farha, O.K. Chemical, thermal and mechanical stabilities of metal-organic frameworks. Nat. Rev. Mater. 2016, 1, 15018. [CrossRef]

35. Velásquez-Hernández, M.d.J.; Linares-Moreau, M.; Astria, E.; Carraro, F.; Alyami, M.Z.; Khashab, N.M.; Sumby, C.J.; Doonan, C.J.; Falcaro, P. Towards applications of bioentities@ MOFs in biomedicine. Coord. Chem. Rev. 2021, 429, 213651. [CrossRef] 
36. Kong, X.-J.; Li, J.-R. An Overview of Metal-Organic Frameworks for Green Chemical Engineering. Nat. Rev. Mater. 2021, 7, 1115-1139. [CrossRef]

37. Plum, L.M.; Rink, L.; Haase, H. The Essential Toxin: Impact of Zinc on Human Health. Int. J. Environ. Res. Public Health 2010, 7 , 1342-1365. [CrossRef]

38. Prasad, A.S.J.M. Zinc in human health: Effect of zinc on immune cells. Mol. Med. 2008, 14, 353-357. [CrossRef]

39. Borda, L.J.; Wikramanayake, T.C. Seborrheic Dermatitis and Dandruff: A Comprehensive Review. J. Clin. Investig. Dermatol. 2015 3, 10. [CrossRef]

40. He, S.; Wu, L.; Li, X.; Sun, H.; Xiong, T.; Liu, J.; Huang, C.; Xu, H.; Sun, H.; Chen, W.; et al. Metal-organic frameworks for advanced drug delivery. Acta Pharm. Sin. B 2021, 11, 2362-2395. [CrossRef]

41. Raptopoulou, C.P. Metal-Organic Frameworks: Synthetic Methods and Potential Applications. Materials 2021, 14, 310. [CrossRef]

42. Bazargan, M.; Ghaemi, F.; Amiri, A.; Mirzaei, M. Metal-organic framework-based sorbents in analytical sample preparation. Coord. Chem. Rev. 2021, 445, 214107. [CrossRef]

43. Yap, M.H.; Fow, K.L.; Chen, G. Environment. Synthesis and applications of MOF-derived porous nanostructures. Green Energy Environ. 2017, 2, 218-245. [CrossRef]

44. Feng, J.; Yang, Z.; Yang, D.; Ren, X.; Zhu, X.; Jin, Z.; Zi, W.; Wei, Q.; Liu, S. (Frank) E-beam evaporated Nb2O5 as an effective electron transport layer for large flexible perovskite solar cells. Nano Energy 2017, 36, 1-8. [CrossRef]

45. Pichon, A.; Lazuen-Garay, A.; James, S.L. Solvent-free synthesis of a microporous metal-organic framework. CrystEngComm 2006 8, 211-214. [CrossRef]

46. Burrows, A.D.; Fisher, L.C.; Hodgson, D.; Mahon, M.F.; Cessford, N.F.; Düren, T.; Richardson, C.; Rigby, S.P. The synthesis, structures and reactions of zinc and cobalt metal-organic frameworks incorporating an alkyne-based dicarboxylate linker. CrystEngComm 2012, 14, 188-192. [CrossRef]

47. Sim, J.; Yim, H.; Ko, N.; Choi, S.B.; Oh, Y.; Park, H.J.; Park, S.; Kim, J.J.D.T. Gas adsorption properties of highly porous met-al-organic frameworks containing functionalized naphthalene dicarboxylate linkers. Dalton Trans. 2014, 43, 18017-18024. [CrossRef]

48. Eddaoudi, M.; Kim, J.; Rosi, N.; Vodak, D.; Wachter, J.; O’Keeffe, M.; Yaghi, O.M. Systematic Design of Pore Size and Functionality in Isoreticular MOFs and Their Application in Methane Storage. Science 2002, 295, 469-472. [CrossRef]

49. Song, L.; Zhang, J.; Sun, L.; Xu, F.; Li, F.; Zhang, H.; Si, X.; Jiao, C.; Li, Z.; Liu, S.; et al. Mesoporous metal-organic frameworks: Design and applications. Energy Environ. Sci. 2012, 5, 7508-7520. [CrossRef]

50. Kim, H.; Hong, C.S. MOF-74-type frameworks: Tunable pore environment and functionality through metal and ligand modification. CrystEngComm 2021, 23, 1377-1387. [CrossRef]

51. Keskin, S.; Kızılel, S.J.I.; Research, E.C. Biomedical applications of metal organic frameworks. Ind. Eng. Chem. Res. 2011, 50, 1799-1812. [CrossRef]

52. Wan, H.; Chen, C.; Wu, Z.; Que, Y.; Feng, Y.; Wang, W.; Wang, L.; Guan, G.; Liu, X.J.C. Encapsulation of heteropolyan-ion-based ionic liquid within the metal-organic framework MIL-100 (Fe) for biodiesel production. Chem CatChem 2015, 7, 441-449. [CrossRef]

53. Wei, J.; Liang, Y.; Hu, Y.; Kong, B.; Zhang, J.; Gu, Q.; Tong, Y.; Wang, X.; Jiang, S.P.; Wang, H.J.A.C. Hydrothermal Synthesis of Metal-Polyphenol Coordination Crystals and Their Derived Metal/N-doped Carbon Composites for Oxygen Electrocatalysis. Angew. Chem. Int. Ed. 2016, 128, 12658-12662. [CrossRef]

54. Nikam, A.V.; Prasad, B.L.V.; Kulkarni, A.A. Wet chemical synthesis of metal oxide nanoparticles: A review. CrystEngComm 2018, 20, 5091-5107. [CrossRef]

55. Hwang, J.; Ejsmont, A.; Freund, R.; Goscianska, J.; Schmidt, B.V.K.J.; Wuttke, S. Controlling the morphology of metal-organic frameworks and porous carbon materials: Metal oxides as primary architecture-directing agents. Chem. Soc. Rev. 2020, 49, 3348-3422. [CrossRef] [PubMed]

56. Mendiratta, S.; Usman, M.; Chang, C.-C.; Lee, Y.-C.; Chen, J.-W.; Wu, M.-K.; Lin, Y.-C.; Hsu, C.-P.; Lu, K.-L. Zn(ii)-based metalorganic framework: An exceptionally thermally stable, guest-free low dielectric material. J. Mater. Chem. C 2017, 5, 1508-1513. [CrossRef]

57. Kharissova, O.V.; Kharisov, B.I.; Jiménez-Pérez, V.M.; Flores, B.M.; Méndez, U.O. Ultrasmall particles and nanocom-posites: State of the art. RSC Adv. 2013, 3, 22648-22682. [CrossRef]

58. Čelič, T.B.; Mazaj, M.; Guillou, N.; Elkaim, E.; El Roz, M.; Thibault-Starzyk, F.; Mali, G.; Rangus, M.; Čendak, T.; Kaučič, V.; et al. Study of Hydrothermal Stability and Water Sorption Characteristics of 3-Dimensional Zn-Based Trimesate. J. Phys. Chem. C 2013, 117, 14608-14617. [CrossRef]

59. De Lima Neto, O.J.; de Oliveira Frós, A.C.; Barros, B.S.; de Farias Monteiro, A.F.; Kulesza, J. Rapid and efficient electrochem-ical synthesis of a zinc-based nano-MOF for Ibuprofen adsorption. New J. Chem. 2019, 43, 5518-5524. [CrossRef]

60. Ma, D.-Y.; Xie, J.; Zhu, Z.; Huang, H.; Chen, Y.; Su, R.; Zhu, H. Drug delivery and selective $\mathrm{CO}_{2}$ adsorption of a bio-based porous zinc-organic framework from 2,5-furandicarboxylate ligand. Inorg. Chem. Commun. 2017, 86, 128-132. [CrossRef]

61. Li, Z.-Q.; Qiu, L.-G.; Wang, W.; Xu, T.; Wu, Y.; Jiang, X. Fabrication of nanosheets of a fluorescent metal-organic framework [Zn $(\mathrm{BDC})\left(\mathrm{H}_{2} \mathrm{O}\right)$ ] n $(\mathrm{BDC}=1$,4-benzenedicarboxylate): Ultrasonic synthesis and sensing of ethylamine. Inorg. Chem. Commun. 2008, 11, 1375-1377. [CrossRef]

62. Vaitsis, C.; Sourkouni, G.; Argirusis, C. Metal Organic Frameworks (MOFs) and ultrasound: A review. Ultrason. Sonochem. 2019, 52, 106-119. [CrossRef] 
63. Safarifard, V.; Morsali, A. Facile preparation of nanocubes zinc-based metal-organic framework by an ultrasound-assisted synthesis method; precursor for the fabrication of zinc oxide octahedral nanostructures. Ultrason. Sonochem. 2018, 40, 921-928. [CrossRef] [PubMed]

64. Masoomi, M.Y.; Bagheri, M.; Morsali, A. High adsorption capacity of two Zn-based metal-organic frameworks by ultra-sound assisted synthesis. Ultrason. Sonochem. 2016, 33, 54-60. [CrossRef] [PubMed]

65. Akbarzadeh, F.; Motaghi, M.; Chauhan, N.P.S.; Sargazi, G. A novel synthesis of new antibacterial nanostructures based on Zn-MOF compound: Design, characterization and a high performance application. Heliyon 2020, 6, e03231. [CrossRef] [PubMed]

66. Wiwasuku, T.; Othong, J.; Boonmak, J.; Ervithayasuporn, V.; Youngme, S. Sonochemical synthesis of microscale Zn(ii)-MOF with dual Lewis basic sites for fluorescent turn-on detection of $\mathrm{Al}^{3+}$ and methanol with low detection limits. Dalton Trans. 2020, 49, 10240-10249. [CrossRef] [PubMed]

67. da Silveira Pinto, L.S.; de Souza, M.V. Sonochemistry as a general procedure for the synthesis of coumarins, including mul-tigram synthesis. Synthesis 2017, 49, 2677-2682.

68. Liu, W.; Pan, Y.; Xiao, W.; Xu, H.; Liu, D.; Ren, F.; Peng, X.; Liu, J. Recent developments on zinc (ii) metal-organic frame-work nanocarriers for physiological pH-responsive drug delivery. Med. Chem. Comm. 2019, 10, 2038-2051. [CrossRef]

69. Ranjbar, M.; Pardakhty, A.; Amanatfard, A.; Asadipour, A. Efficient drug delivery of $\beta$-estradiol encapsulated in Zn-metal-organic framework nanostructures by microwave-assisted coprecipitation method. Drug Des. Dev. Ther. 2018, 12, 2635-2643. [CrossRef] [PubMed]

70. Khan, N.A.; Kang, I.J.; Seok, H.Y.; Jhung, S.H. Facile synthesis of nano-sized metal-organic frameworks, chromiumbenzenedicarboxylate, MIL-101. Chem. Eng. J. 2011, 166, 1152-1157. [CrossRef]

71. Sabouni, R.; Kazemian, H.; Rohani, S. Microwave Synthesis of the CPM-5 Metal Organic Framework. Chem. Eng. Technol. 2012, 35, 1085-1092. [CrossRef]

72. Choi, J.-S.; Son, W.-J.; Kim, J.; Ahn, W.-S. Metal-organic framework MOF-5 prepared by microwave heat-ing: Factors to be considered. Microporous Mesoporous Mater. 2008, 116, 727-731. [CrossRef]

73. Hwang, J.; Yan, R.; Oschatz, M.; Schmidt, B.V.K.J. Solvent mediated morphology control of zinc MOFs as carbon templates for application in supercapacitors. J. Mater. Chem. A 2018, 6, 23521-23530. [CrossRef]

74. Hou, C.; Zou, L.; Xu, Q. A Hydrangea-Like Superstructure of Open Carbon Cages with Hierarchical Porosity and Highly Active Metal Sites. Adv. Mater. 2019, 31, e1904689. [CrossRef]

75. Doustkhah, E.; Hassandoost, R.; Khataee, A.; Luque, R.; Assadi, M.H.N. Hard-templated metal-organic frameworks for advanced applications. Chem. Soc. Rev. 2021, 50, 2927-2953. [CrossRef]

76. Zhang, F.; Wei, Y.; Wu, X.; Jiang, H.; Wang, W.; Li, H. Hollow Zeolitic Imidazolate Framework Nanospheres as Highly Efficient Cooperative Catalysts for [3+3] Cycloaddition Reactions. J. Am. Chem. Soc. 2014, 136, 13963-13966. [CrossRef]

77. Wang, J.; Tang, J.; Ding, B.; Chang, Z.; Hao, X.; Takei, T.; Kobayashi, N.; Bando, Y.; Zhang, X.; Yamauchi, Y. Self-Template-Directed Metal-Organic Frameworks Network and the Derived Honeycomb-Like Carbon Flakes via Con-finement Pyrolysis. Small 2018, 14, 1704461. [CrossRef] [PubMed]

78. El-Hankari, S.; Aguilera-Sigalat, J.; Bradshaw, D. J Surfactant-assisted ZnO processing as a versatile route to ZIF composites and hollow architectures with enhanced dye adsorption. J. Mater. Chem. A 2016, 4, 13509-13518. [CrossRef]

79. Koo, W.-T.; Choi, S.-J.; Jang, J.-S.; Kim, I.-D. Metal-Organic Framework Templated Synthesis of Ultrasmall Catalyst Loaded $\mathrm{ZnO} / \mathrm{ZnCo}_{2} \mathrm{O}_{4}$ Hollow Spheres for Enhanced Gas Sensing Properties. Sci. Rep. 2017, 7, srep45074. [CrossRef] [PubMed]

80. An, J.; Fiorella, R.; Geib, S.J.; Rosi, N.L. Synthesis, Structure, Assembly, and Modulation of the CO2 Adsorption Properties of a Zinc-Adeninate Macrocycle. J. Am. Chem. Soc. 2009, 131, 8401-8403. [CrossRef]

81. Qin, J.-S.; Du, D.-Y.; Li, W.-L.; Zhang, J.-P.; Li, S.-L.; Su, Z.-M.; Wang, X.-L.; Xu, Q.; Shao, K.-Z.; Lan, Y.-Q. N-rich zeolite-like metal-organic framework with sodalite topology: High $\mathrm{CO}_{2}$ uptake, selective gas adsorption and efficient drug delivery. Chem. Sci. 2012, 3, 2114-2118. [CrossRef]

82. Su, H.; Sun, F.; Jia, J.; He, H.; Wang, A.; Zhu, G. A highly porous medical metal-organic framework constructed from bioactive curcumin. Chem. Commun. 2015, 51, 5774-5777. [CrossRef]

83. Huong, T.T.T.; Thanh, P.N. Metal-organic frameworks: State-of-the-art material for gas capture and storage. VNU J. Sci. Math. Phys. 2016, 32, 67-85.

84. Dong, K.; Wang, Z.; Zhang, Y.; Ren, J.; Qu, X. Metal-organic framework-based nanoplatform for intracellular environmentresponsive endo/lysosomal escape and enhanced cancer therapy. ACS Appl. Mater. Interfaces 2018, 10, 31998-32005. [CrossRef]

85. Glover, T.G.; Peterson, G.W.; Schindler, B.J.; Britt, D.; Yaghi, O. MOF-74 building unit has a direct impact on toxic gas ad-sorption. Chem. Eng. Sci. 2011, 66, 163-170. [CrossRef]

86. Pang, J.; Yuan, S.; Qin, J.-S.; Lollar, C.T.; Huang, N.; Li, J.; Wang, Q.; Wu, M.; Yuan, D.; Hong, M.J. Tuning the ionicity of stable metal-organic frameworks through ionic linker installation. J. Am. Chem. Soc. 2019, 141, 3129-3136. [CrossRef]

87. Yaqoob, A.A.; Ahmad, H.; Parveen, T.; Ahmad, A.; Oves, M.; Ismail, I.M.I.; Qari, H.A.; Umar, K.; Ibrahim, M.N.M. Recent Advances in Metal Decorated Nanomaterials and Their Various Biological Applications: A Review. Front. Chem. $2020,8,341$. [CrossRef]

88. Sun, C.-Y.; Liu, S.-X.; Liang, D.-D.; Shao, K.-Z.; Ren, Y.-H.; Su, Z.-M. Highly Stable Crystalline Catalysts Based on a Microporous Metal-Organic Framework and Polyoxometalates. J. Am. Chem. Soc. 2009, 131, 1883-1888. [CrossRef] [PubMed] 
89. Ishida, T.; Nagaoka, M.; Akita, T.; Haruta, M. Deposition of Gold Clusters on Porous Coordination Polymers by Solid Grinding and Their Catalytic Activity in Aerobic Oxidation of Alcohols. Chem. A Eur. J. 2008, 14, 8456-8460. [CrossRef] [PubMed]

90. Xue, Y.; Zheng, S.; Xue, H.; Pang, H. Metal-organic framework composites and their electrochemical applications. J. Mater. Chem. A 2019, 7, 7301-7327. [CrossRef]

91. Tsivion, E.; Long, J.R.; Head-Gordon, M. Hydrogen Physisorption on Metal-Organic Framework Linkers and Metalated Linkers: A Computational Study of the Factors That Control Binding Strength. J. Am. Chem. Soc. 2014, 136, 17827-17835. [CrossRef] [PubMed]

92. Ren, H.; Zhang, L.; An, J.; Wang, T.; Li, L.; Si, X.; He, L.; Wu, X.; Wang, C.; Su, Z. Polyacrylic acid@ zeolitic imidazolate framework-8 nanoparticles with ultrahigh drug loading capability for $\mathrm{pH}$-sensitive drug release. Chem. Commun. 2014, 50, 1000-1002. [CrossRef]

93. Sun, C.-Y.; Qin, C.; Wang, X.-L.; Yang, G.-S.; Shao, K.-Z.; Lan, Y.-Q.; Su, Z.-M.; Huang, P.; Wang, C.-G.; Wang, E.-B. Zeolitic imidazolate framework-8 as efficient $\mathrm{pH}$-sensitive drug delivery vehicle. Dalton Trans. 2012, 41, 6906-6909. [CrossRef]

94. Silva, J.S.; Silva, J.Y.; de Sá, G.F.; Araújo, S.S.; Filho, M.A.G.; Ronconi, C.M.; Santos, T.C.; Júnior, S.A. Multifunctional system polyaniline-decorated ZIF-8 nanoparticles as a new chemo-photothermal platform for cancer therapy. ACS Omega 2018, 3, 12147-12157. [CrossRef] [PubMed]

95. Chowdhuri, A.R.; Singh, T.; Ghosh, S.K.; Sahu, S.K. One-pot synthesis of folic acid encapsulated upconversion nanoscale metal organic frameworks for targeting, imaging and $\mathrm{pH}$ responsive drug release. Dalton Trans. 2016, 45, 18120-18132. [CrossRef] [PubMed]

96. Lin, W.; Hu, Q.; Jiang, K.; Cui, Y.; Yang, Y.; Qian, G. A porous Zn-based metal-organic framework for $\mathrm{pH}$ and temperature dual-responsive controlled drug release. Microporous Mesoporous Mater. 2017, 249, 55-60. [CrossRef]

97. Song, B.-H.; Ding, X.; Zhang, Z.-F.; An, G.-F. Efficient drug delivery of 5-fluorouracil by a biocompatible Zn-metal-organic framework nanostructure and anti-liver cancer activity study. J. Iran. Chem. Soc. 2018, 16, 333-340. [CrossRef]

98. Zheng, H.; Zhang, Y.; Liu, L.; Wan, W.; Guo, P.; Nyström, A.M.; Zou, X. One-pot Synthesis of Metal-Organic Frameworks with Encapsulated Target Molecules and Their Applications for Controlled Drug Delivery. J. Am. Chem. Soc. 2016, 138, 962-968. [CrossRef] [PubMed]

99. Tacar, O.; Sriamornsak, P.; Dass, C.R. Doxorubicin: An update on anticancer molecular action, toxicity and novel drug delivery systems. J. Pharm. Pharmacol. 2013, 65, 157-170. [CrossRef]

100. Liang, Z.; Yang, Z.; Yuan, H.; Wang, C.; Qi, J.; Liu, K.; Cao, R.; Zheng, H. A protein@ metal-organic framework nanocompo-site for $\mathrm{pH}$-triggered anticancer drug delivery. Dalton Trans. 2018, 47, 10223-10228. [CrossRef]

101. Zheng, C.; Wang, Y.; Phua, S.Z.F.; Lim, W.Q.; Zhao, Y. ZnO-DOX@ ZIF-8 core-shell nanoparticles for pH-responsive drug delivery. ACS Biomater. Sci. Eng. 2017, 3, 2223-2229. [CrossRef]

102. Jiang, Z.; Wang, Y.; Sun, L.; Yuan, B.; Tian, Y.; Xiang, L.; Li, Y.; Li, Y.; Li, J.; Wu, A. Dual ATP and pH responsive ZIF-90 nano system with favorable biocompatibility and facile post-modification improves therapeutic outcomes of triple negative breast cancer in vivo. Biomaterials 2019, 197, 41-50. [CrossRef]

103. Zhang, F.-M.; Dong, H.; Zhang, X.; Sun, X.-J.; Liu, M.; Yang, D.-D.; Liu, X.; Wei, J.-Z. Postsynthetic Modification of ZIF-90 for Potential Targeted Codelivery of Two Anticancer Drugs. ACS Appl. Mater. Interfaces 2017, 9, 27332-27337. [CrossRef] [PubMed]

104. Xie, Z.; Cai, X.; Sun, C.; Liang, S.; Shao, S.; Huang, S.; Cheng, Z.; Pang, M.; Xing, B.; Al Kheraif, A.; et al. O2-Loaded pHResponsive Multifunctional Nanodrug Carrier for Overcoming Hypoxia and Highly Efficient Chemo-Photodynamic Cancer Therapy. Chem. Mater. 2019, 31, 483-490. [CrossRef]

105. Li, Q.-L.; Wang, J.-P.; Liu, W.-C.; Zhuang, X.-Y.; Liu, J.-Q.; Fan, G.-L.; Li, B.-H.; Lin, W.-N.; Man, J.-H. A new (4,8)-connected topological MOF as potential drug delivery. Inorg. Chem. Commun. 2015, 55, 8-10. [CrossRef]

106. Deng, K.; Dong, L.; Li, Q.; Gou, Y.; Zhang, P.; Ren, X.; Zhong, H. Drug Release Behaviors of a Novel pH/Temperature-Responsive Chitosan-Poly(N-acryloylglycinate) Hydrogel. J. Appl. Polym. Sci. 2011, 120, 3297-3303. [CrossRef]

107. Saeb, M.; Rabiee, N.; Mozafari, M.; Mostafavi, E. Metal-Organic Frameworks (MOFs)-Based Nanomaterials for Drug Delivery. Materials 2021, 14, 3652. [CrossRef] [PubMed]

108. Seabra, A.B.; Durána, N. Nitric oxide-releasing vehicles for biomedical applications. J. Mater. Chem. 2010, 20 , 1624-1637. [CrossRef]

109. Zhang, M.; Qiao, R.; Hu, J. Engineering metal-organic frameworks (MOFs) for controlled delivery of physiological gase-ous transmitters. Nanomaterials 2020, 10, 1134. [CrossRef]

110. Shimomura, S.; Higuchi, M.; Matsuda, R.; Yoneda, K.; Hijikata, Y.; Kubota, Y.; Mita, Y.; Kim, J.; Takata, M.; Kitagawa, S. Se-lective sorption of oxygen and nitric oxide by an electron-donating flexible porous coordination polymer. Nat. Chem. 2010, 2, 633-637. [CrossRef]

111. Zhang, Q.; Wang, C.-F.; Lv, Y.-K. Luminescent switch sensors for the detection of biomolecules based on metal-organic frameworks. Analyst 2018, 143, 4221-4229. [CrossRef]

112. Cattaneo, D.; Warrender, S.J.; Duncan, M.J.; Kelsall, C.J.; Doherty, M.K.; Whitfield, P.D.; Megson, I.L.; Morris, R.E. Tuning the nitric oxide release from CPO-27 MOFs. RSC Adv. 2016, 6, 14059-14067. [CrossRef]

113. Chaemchuen, S.; Xiao, X.; Klomkliang, N.; Yusubov, M.S.; Verpoort, F. Tunable metal-organic frameworks for heat trans-formation applications. Nanomaterials 2018, 8, 661. [CrossRef] [PubMed] 
114. Velasco, M.I.; Acosta, R.H.; Marmisolleé, W.A.; Azzaroni, O.; Rafti, M. Modulation of Hydrophilic/Hydrophobic Character of Porous Environments in Metal-Organic Frameworks via Direct Polymer Capping Probed by NMR Diffusion Measurements. J. Phys. Chem. C 2019, 123, 21076-21082. [CrossRef]

115. Chowdhury, M.A. Metal-organic-frameworks for biomedical applications in drug delivery, and as MRI contrast agents. J. Biomed. Mater. Res. Part A 2017, 105, 1184-1194. [CrossRef] [PubMed]

116. Liu, J.; Huang, J.; Zhang, L.; Lei, J. Multifunctional metal-organic framework heterostructures for enhanced cancer therapy. Chem. Soc. Rev. 2020, 50, 1188-1218. [CrossRef]

117. Guo, C.; Xu, S.; Arshad, A.; Wang, L. A pH-responsive nanoprobe for turn-on 19 F-magnetic resonance imaging. Chem. Commun. 2018, 54, 9853-9856. [CrossRef]

118. Chowdhuri, A.R.; Bhattacharya, D.; Sahu, S.K. Magnetic nanoscale metal organic frameworks for potential targeted anti-cancer drug delivery, imaging and as an MRI contrast agent. Dalton Trans. 2016, 45, 2963-2973. [CrossRef]

119. Duman, F.D.; Forgan, R.S. Applications of nanoscale metal-organic frameworks as imaging agents in biology and medicine. J. Mater. Chem. B 2021, 9, 3423-3449. [CrossRef]

120. Dekrafft, K.E.; Boyle, W.S.; Burk, L.M.; Zhou, O.Z.; Lin, W. Zr- and Hf-based nanoscale metal-organic frameworks as contrast agents for computed tomography. J. Mater. Chem. 2012, 22, 18139-18144. [CrossRef]

121. Kirsch, J.; Siltanen, C.; Zhou, Q.; Revzin, A.; Simonian, A.; Katz, E.; Katz, E.; Wang, J.; Bocharova, V.; Wang, J.; et al. Biosensor technology: Recent advances in threat agent detection and medicine. Chem. Soc. Rev. 2013, 42, 8733. [CrossRef]

122. Turner, A.P.F. Biosensors: Sense and sensibility. Chem. Soc. Rev. 2013, 42, 3184-3196. [CrossRef] [PubMed]

123. Ding, G.; Yuan, J.; Jin, F.; Zhang, Y.; Han, L.; Ling, X.; Zhao, H.; Ma, W. High-performance all-polymer nonfullerene solar cells by employing an efficient polymer-small molecule acceptor alloy strategy. Nano Energy 2017, 36, 356-365. [CrossRef]

124. Wang, S.; McGuirk, C.M.; d'Aquino, A.; Mason, J.A.; Mirkin, C.A. Metal-organic framework nanoparticles. Adv. Mater. 2018, 30, 1800202. [CrossRef]

125. An, J.; Shade, C.M.; Chengelis-Czegan, D.A.; Petoud, S.; Rosi, N.L. Zinc-Adeninate Metal-Organic Framework for Aqueous Encapsulation and Sensitization of Near-infrared and Visible Emitting Lanthanide Cations. J. Am. Chem. Soc. 2011, 133, 1220-1223. [CrossRef]

126. Ma, D.; Li, B.; Zhou, X.; Zhou, Q.; Liu, K.; Zeng, G.; Li, G.; Shi, Z.; Feng, S. A dual functional MOF as a luminescent sensor for quantitatively detecting the concentration of nitrobenzene and temperature. Chem. Commun. 2013, 49, 8964-8966. [CrossRef]

127. Saeed, A.; Hussain, D.; Saleem, S.; Mehdi, S.; Javeed, R.; Jabeen, F.; Najam-ul-Haq, M. Metal-organic framework-based affin-ity materials in proteomics. Anal. Bioanal. Chem. 2019, 411, 1745-1759. [CrossRef]

128. Wang, J.; Li, J.; Wang, Y.; Gao, M.; Zhang, X.; Yang, P. Development of Versatile Metal-Organic Framework Functionalized Magnetic Graphene Core-Shell Biocomposite for Highly Specific Recognition of Glycopeptides. ACS Appl. Mater. Interfaces 2016, 8, 27482-27489. [CrossRef]

129. Saleem, S.; Sajid, M.S.; Hussain, D.; Fatima, B.; Jabeen, F.; Najam-Ul-Haq, M.; Saeed, A. Highly porous terpolymer-ZIF8@BA MOF composite for identification of mono- and multi-glycosylated peptides/proteins using MS-based bottom-up approach. Microchim. Acta 2020, 187, 1-9. [CrossRef] [PubMed]

130. Sawayama, T.; Wang, Y.; Watanabe, T.; Takayanagi, M.; Yamamoto, T.; Hosono, N.; Uemura, T. Metal-Organic Frameworks for Practical Separation of Cyclic and Linear Polymers. Angew. Chem. Int. Ed. 2021, 60, 11830-11834. [CrossRef]

131. Oe, N.; Hosono, N.; Uemura, T. Revisiting molecular adsorption: Unconventional uptake of polymer chains from solu-tion into sub-nanoporous media. Chem. Sci. 2021, 12, 12576-12586. [CrossRef]

132. Le Ouay, B.; Watanabe, C.; Mochizuki, S.; Takayanagi, M.; Nagaoka, M.; Kitao, T.; Uemura, T. Selective sorting of polymers with different terminal groups using metal-organic frameworks. Nat. Commun. 2018, 9, 1-8. [CrossRef]

133. Kim, T.-K.; Kim, T.; Park, H.; Lee, I.; Jo, A.; Choi, K.; Zoh, K.-D. Degradation of ciprofloxacin and inactivation of ciprofloxa-cin resistant E. faecium during UV-LED (275 nm)/chlorine process. Chem. Eng. J. 2020, 394, 124803. [CrossRef]

134. Fan, Y.; Moon, J.J. Nanoparticle Drug Delivery Systems Designed to Improve Cancer Vaccines and Immunotherapy. Vaccines 2015, 3, 662-685. [CrossRef] [PubMed]

135. Miao, Y.B.; Pan, W.Y.; Chen, K.H.; Wei, H.J.; Mi, F.L.; Lu, M.Y.; Chang, Y.; Sung, H.W. Engineering a Nanoscale Al-MOF-Armored Antigen Carried by a "Trojan Horse" -Like Platform for Oral Vaccination to Induce Potent and Long-Lasting Immunity. Adv. Funct. Mater. 2019, 29, 1904828. [CrossRef]

136. Zhang, Y.; Wang, F.; Ju, E.; Liu, Z.; Chen, Z.; Ren, J.; Qu, X.J. Metal-organic-framework-based vaccine platforms for en-hanced systemic immune and memory response. Adv. Funct. Mater. 2016, 26, 6454-6461. [CrossRef]

137. Duan, F.; Feng, X.; Yang, X.; Sun, W.; Jin, Y.; Liu, H.; Ge, K.; Li, Z.; Zhang, J.J. A simple and powerful co-delivery system based on $\mathrm{pH}$-responsive metal-organic frameworks for enhanced cancer immunotherapy. Biomaterials 2017, 122, 23-33. [CrossRef] [PubMed]

138. Jung, S.; Lee, J.; Seo, J.; Kim, U.; Choi, Y.; Park, H. Development of Annealing-Free, Solution-Processable Inverted Organic Solar Cells with N-Doped Graphene Electrodes using Zinc Oxide Nanoparticles. Nano Lett. 2018, 18, 1337-1343. [CrossRef]

139. Esfahanian, M.; Ghasemzadeh, M.A.; Razavian, S.M.H. Synthesis, identification and application of the novel met-al-organic framework Fe3O4@ PAA@ ZIF-8 for the drug delivery of ciprofloxacin and investigation of antibacterial activity. Artif. Cells Nanomed. Biotechnol. 2019, 47, 2024-2030. [CrossRef] 
140. Bahr, D.; Reid, J.; Mook, W.; Bauer, C.; Stumpf, R.; Skulan, A.; Moody, N.; Simmons, B.; Shindel, M.; Allendorf, M.J. Me-chanical properties of cubic zinc carboxylate IRMOF-1 metal-organic framework crystals. Phys. Rev. B 2007, 76, 184106. [CrossRef]

141. Beg, S.; Rahman, M.; Jain, A.; Saini, S.; Midoux, P.; Pichon, C.; Ahmad, F.J.; Akhter, S.J. Nanoporous metal organic frame-works as hybrid polymer-metal composites for drug delivery and biomedical applications. Drug Discov. Today 2017, 22, 625-637. [CrossRef]

142. Zhao, H.-X.; Zou, Q.; Sun, S.-K.; Yu, C.; Zhang, X.; Li, R.-J.; Fu, Y.-Y. Theranostic metal-organic framework core-shell composites for magnetic resonance imaging and drug delivery. Chem. Sci. 2016, 7, 5294-5301. [CrossRef] [PubMed]

143. Szilágyi, P.Á.; Lutz, M.; Gascon, J.; Juan-Alcañiz, J.; van Esch, J.; Kapteijn, F.; Geerlings, H.; Dam, B.; van de Krol, R. MOF@MOF core-shell vs. Janus particles and the effect of strain: Potential for guest sorption, separation and sequestration. CrystEngComm 2013, 15, 6003-6008. [CrossRef]

144. Zhou, N.; Su, F.; Guo, C.; He, L.; Jia, Z.; Wang, M.; Jia, Q.; Zhang, Z.; Lu, S. Two-dimensional oriented growth of Zn-MOF-on-ZrMOF architecture: A highly sensitive and selective platform for detecting cancer markers. Biosens. Bioelectron. 2019, 123, 51-58. [CrossRef]

145. He, L.; Liu, Y.; Liu, J.; Xiong, Y.; Zheng, J.; Liu, Y.; Tang, Z. Core-shell noble-metal@ metal-organic-framework nanoparti-cles with highly selective sensing property. Angew. Chem. Int. Ed. 2013, 125, 3829-3833. [CrossRef]

146. Vasconcelos, I.B.; da Silva, T.G.; Militão, G.C.G.; Soares, T.A.; Rodrigues, N.M.; Rodrigues, M.O.; da Costa, N.B.; Freire, R.O.; Junior, S.A. Cytotoxicity and slow release of the anti-cancer drug doxorubicin from ZIF-8. RSC Adv. 2012, 2, 9437-9442. [CrossRef]

147. Tamames-Tabar, C.; Cunha, D.; Imbuluzqueta, E.; Ragon, F.; Serre, C.; Blanco-Prieto, M.J.; Horcajada, P. Cytotoxicity of nanoscaled metal-organic frameworks. J. Mater. Chem. B 2014, 2, 262-271. [CrossRef]

148. Abazari, R.; Mahjoub, A.R.; Ataei, F.; Morsali, A.; Carpenter-Warren, C.L.; Mehdizadeh, K.; Slawin, A.M.J. Chitosan immobilization on bio-MOF nanostructures: A biocompatible $\mathrm{pH}$-responsive nanocarrier for doxorubicin release on MCF-7 cell lines of human breast cancer. Inorg. Chem. 2018, 57, 13364-13379. [CrossRef] [PubMed]

149. Ruyra, À.; Yazdi, A.; Espín, J.; Carné-Sánchez, A.; Roher, N.; Lorenzo, J.; Imaz, I.; Maspoch, D. Synthesis, Culture Medium Stability, and In Vitro and In Vivo Zebrafish Embryo Toxicity of Metal-Organic Framework Nanoparticles. Chem. A Eur. J. 2015, 21, 2508-2518. [CrossRef]

150. Lian, X.; Fang, Y.; Joseph, E.; Wang, Q.; Li, J.; Banerjee, S.; Lollar, C.; Wang, X.; Zhou, H. Enzyme-MOF (metal-organic framework) composites. Chem. Soc. Rev. 2017, 46, 3386-3401. [CrossRef]

151. Scicluna, M.C.; Vella-Zarb, L. Evolution of nanocarrier drug-delivery systems and recent advancements in co-valent organic framework-drug systems. ACS Appl. Energy Mater. 2020, 3, 3097-3115. [CrossRef]

152. Lismont, M.; Dreesen, L.; Wuttke, S.J. Metal-organic framework nanoparticles in photodynamic therapy: Current status and perspectives. Adv. Funct. Mater. 2017, 27, 1606314. [CrossRef] 